\title{
Extended Wakefulness: Compromised Metabolics in and Degeneration of Locus Ceruleus Neurons
}

\author{
Jing Zhang, ${ }^{1}$ Yan Zhu, ${ }^{2}$ Guanxia Zhan, ${ }^{2}$ Polina Fenik, ${ }^{2}$ Lori Panossian, ${ }^{2}$ Maxime M. Wang, ${ }^{2}$ Shayla Reid, ${ }^{2}$ David Lai, ${ }^{2}$ \\ James G. Davis, ${ }^{3,4}$ Joseph A. Baur, ${ }^{3,4}$ and Sigrid Veasey ${ }^{2}$ \\ ${ }^{1}$ Department of Respiratory and Critical Care Medicine, Peking University First Hospital, Beijing 100034, China, ${ }^{2}$ Center for Sleep and Circadian \\ Neurobiology, Department of Medicine, ${ }^{3}$ Institute for Diabetes, Obesity and Metabolism, and ${ }^{4}$ Department of Physiology, Perelman School of Medicine, \\ University of Pennsylvania, Philadelphia, Pennsylvania 19104
}

\begin{abstract}
Modern society enables a shortening of sleep times, yet long-term consequences of extended wakefulness on the brain are largely unknown. Essential for optimal alertness, locus ceruleus neurons (LCns) are metabolically active neurons that fire at increased rates across sustained wakefulness. We hypothesized that wakefulness is a metabolic stressor to LCns and that, with extended wakefulness, adaptive mitochondrial metabolic responses fail and injury ensues. The nicotinamide adenine dinucleotide-dependent deacetylase sirtuin type 3 (SirT3) coordinates mitochondrial energy production and redox homeostasis. We find that brief wakefulness upregulates SirT3 and antioxidants in LCns, protecting metabolic homeostasis. Strikingly, mice lacking SirT3 lose the adaptive antioxidant response and incur oxidative injury in LCns across brief wakefulness. When wakefulness is extended for longer durations in wild-type mice, SirT3 protein declines in LCns, while oxidative stress and acetylation of mitochondrial proteins, including electron transport chain complex I proteins, increase. In parallel with metabolic dyshomeostasis, apoptosis is activated and LCns are lost. This work identifies mitochondrial stress in LCns upon wakefulness, highlights an essential role for SirT3 activation in maintaining metabolic homeostasis in LCns across wakefulness, and demonstrates that extended wakefulness results in reduced SirT3 activity and, ultimately, degeneration of LCns.
\end{abstract}

Key words: acetylation; locus ceruleus; metabolics; mitochondria; oxidative stress; sleep deprivation

\section{Introduction}

Artificial lighting, longer work commuting times, night-shift work, and increasing availability of computers and televisions have all contributed to shortened sleep times (Centers for Disease Control and Prevention, 2012). Sleep loss, however, impacts negatively on cognitive performance, including mood, attention, memory, and executive function (McCoy and Strecker, 2011). Cognitive impairments are generally considered to be driven by sleep homeostatic influences, including adenosine (Blutstein and Haydon, 2013), although metabolic changes in the brain also occur in response to sleep loss. Specifically, short-term sleep loss increases both antioxidant responses and electron transport chain (ETC) activity in some, but not all, brain regions (Nikonova et al., 2005, 2010; Ramanathan et al., 2010), while extended sleep loss may reduce antioxidant activity and ATP production (Ramanathan et al., 2002). Presently unanswered questions include the following: whether metabolic responses to

Received Oct. 25, 2012; revised Dec. 5, 2013; accepted Jan. 8, 2014.

Author contributions: J.Z., J.A.B., and S.V. designed research; J.Z., Y.Z., G.Z., P.F., L.P., M.M.W., S.R., J.G.D., D.L., and S.V. performed research; J.Z. and S.V. contributed unpublished reagents/analytic tools; J.Z., Y.Z., G.Z., P.F., L.P., M.M.W., D.L., J.G.D., J.A.B., and S.V. analyzed data; J.Z., J.A.B., and S.V. wrote the paper.

J.Z. was supported by the China Scholarship Council. The studies were performed with support from National Institutes of Health Grants R01 HL079555 and HL096037 to S.V.; and R01 DK098656 to J.A.B.

The authors declare no competing financial interests.

Correspondence should be addressed to Sigrid Veasey, University of Pennsylvania, Translational Research Building, 125 South 31st Street, Philadelphia, PA 19104. E-mail: veasey@mail.med.upenn.edu.

DOI:10.1523/JNEUROSCI.5025-12.2014

Copyright $\odot 2014$ the authors $\quad 0270-6474 / 14 / 344418-14 \$ 15.00 / 0$ short- and long-term sleep loss occur within neurons essential for alertness, varying with sleep loss duration; whether select neurons incur significant injury upon extended sleep loss; and what molecular mechanisms underlie metabolic responses to sleep loss.

Essential for optimal cognitive function, noradrenergic locus ceruleus neurons (LCns) are wake-active neurons that exhibit heightened sensitivity to metabolic stress (Murai et al., 1997; Zhu et al., 2007; Panossian et al., 2011). With numerous collaterals, LCns project extensively throughout the cortices and maintain high levels of activity across wakefulness, while firing rates drop significantly in non-rapid eye movement (NREM) sleep and approach quiescence in REM sleep (Aston-Jones and Bloom, 1981). LCns may, therefore, be vulnerable to the metabolic demands of extended wakefulness.

Sirtuin type 3 (SirT3) is a mammalian sirtuin that localizes to the inner mitochondrial membrane, coordinating energy production and redox responses (Bell and Guarente, 2011). As a nicotinamide adenine dinucleotide $\left(\mathrm{NAD}^{+}\right)$-dependent enzyme, SirT3 augments ETC complex I activity and ATP production through deacetylation of complex I proteins, when energy availability diminishes (Ahn et al., 2008). Additionally SirT3 upregulates many antioxidant defenses, including the following: glutathione reduction via activation of isocitrate dehydrogenase 2 and glutathione dehydrogenase (Someya et al., 2010; Yu et al., 2012); FoxO3a activation with resultant upregulation of superoxide dismutase 2 (SOD2) and catalase (Jacobs et al., 2008); and 
direct activation of SOD2 (Qiu et al., 2010). SirT3 activity, however, diminishes with aging, contributing to auditory neuron loss (Someya et al., 2010; Yu et al., 2012). NAD ${ }^{+}$depletion and severe oxidative stress can impair SirT3 activity (Fritz et al., 2011; Wagner et al., 2012). We hypothesized that across short-term wakefulness LCn metabolic homeostasis is maintained effectively via SirT3-dependent pathways; however, when sleep loss is extended, the SirT3 response fails and LCns are lost.

Examining metabolic responses to short- and long-term sleep loss in young adult mice, we discovered that short-term sleep loss elicits an SirT3-dependent antioxidant response that is essential for LCn redox homeostasis across wakefulness. When wakefulness is extended, however, to the extent of several consecutive night shifts, LCn SirT3 activity declines, and metabolic homeostasis is not maintained, as evidenced by mitochondrial protein hyperacetylation and oxidative stress. Importantly, in parallel with metabolic dyshomeostasis, LCn degeneration ensues. These studies establish SirT3 as a critical metabolic rheostat in LCns across wakefulness and identify extended wakefulness as a novel risk factor for LC neurodegeneration.

\section{Materials and Methods}

Mice and study overview. Studies were performed at the University of Pennsylvania with the approval of the Institutional Animal Care and Use Committee and in accordance with the revised National Institutes of Health Office Laboratory Animal Welfare Policy. Male C57BL/6 and J129-SirT3 ${ }^{\text {tm 1.1Fwa }} /$ J (SirT3 $^{-1-}$ ) with wild-type (SirT3wt) genetic background strain for the SirT3 ${ }^{-1-}$ mice, 129S1/SvImJ, were 8 weeks of age at the start of experimentation. Mice were housed in a light/dark environment with lights on from 6:00 A.M. to 6:00 P.M. and fed ad libitum standard rodent chow and water. Ambient temperature and humidity were maintained between 22 and $24^{\circ} \mathrm{C}$ and $40-60 \%$, respectively. $\mathrm{SirT}^{-1-}$ and SirT3wt mice were genotyped for inclusion in this study. The three oligonucleotide primer sequences used were as follows: $5^{\prime}-$ CTT CTG CGG CTC TAT ACA CAG-3' (wild-type forward); 5'-TGC AAC AAG GCT TTA TCT TCC-3' (common); and 5' -TAC TGA ATA TCA GTG GGA ACG-3' (mutant reverse) for an expected SirT3 ${ }^{-1-}$ band at $200 \mathrm{bp}$, and SirT3wt at $562 \mathrm{bp}$.

Surgery and behavioral state recording and analysis. Behavioral states were recorded to measure wakefulness across sleep loss and rested (Rest) conditions, and to characterize wakefulness and sleep/wake activity in one group of SirT3 ${ }^{-1-}$ and SirT3wt mice ( $n=8$ /group). Following ketamine $(80-85 \mathrm{mg} / \mathrm{kg})$ and xylazine $(9 \mathrm{mg} / \mathrm{kg})$ anesthesia, mice were implanted as previously described with silver electroencephalogram (EEG) and electromyogram (EMG) recording wires attached to an electrode connector (Veasey et al., 2000). Mice were connected to a counterweighted recording cable 1 week postoperatively and confirmed to have full mobility within their cages, including rearing/climbing behaviors. Signals were amplified, digitized, and recorded as previously described (Veasey et al., 2004). Raw EEG and EMG data were exported into the SleepSign sleep/wake program (version 3.0, Kissei) for analysis. Wakesleep states were scored in $4 \mathrm{~s}$ epochs. The wake state was identified by the presence of low-amplitude, high-frequency EEG ( $>10 \%$ waveforms of $>12 \mathrm{~Hz}$ ) and relatively high-amplitude EMG. NREM sleep (NREMS) was identified by the presence of EEG delta waves $(0.5-4 \mathrm{~Hz})$ comprising $>30 \%$ of EEG waveforms/epoch, higher frequencies $(13-30 \mathrm{~Hz})$ comprising $<10 \%$, and a lower amplitude EMG. REMS was identified by the presence of theta $(5-10 \mathrm{~Hz})$ comprising $>20 \%$ of EEG waveforms/epoch with a low EMG amplitude. Each $4 \mathrm{~s}$ epoch of automated scoring that was included in analyses of sleep deprivation or sleep/wake studies was visually checked with its corresponding EEG spectral data and rescored as necessary to fully optimize behavioral state accuracy.

Enriched environment sleep loss protocols. A previously validated, enriched, novel environment (Gompf et al., 2010) was used to promote spontaneous exploratory wakefulness. The short-term wakefulness (Sh Wake) period selected was $3 \mathrm{~h}$ during the lights-on period. With zeitgeber time $0 \mathrm{~h}$ (ZT0) referenced to the onset of the lights-on period, Sh
Table 1. Primary antibodies

\begin{tabular}{lllll}
\hline $\begin{array}{l}\text { Primary } \\
\text { antibodies }\end{array}$ & Catalog number/company & $\begin{array}{l}\text { IHC } \\
\text { dilution }\end{array}$ & $\begin{array}{l}\text { WB } \\
\text { dilution }\end{array}$ & $\begin{array}{l}\text { WB band size } \\
(\mathrm{kDa})\end{array}$ \\
\hline Acetyl-Lysine & 9441 /Cell Signaling Technology & $\mathrm{N} / \mathrm{A}$ & $1: 500$ & $\mathrm{~N} / \mathrm{A}$ \\
Catalase & ab1877/Abcam & $1: 250$ & $1: 1500$ & 65 \\
c-fos & Ab-5/EMD Millipore & $1: 2000$ & $\mathrm{~N} / \mathrm{A}$ & $\mathrm{N} / \mathrm{A}$ \\
CC3 & $9664 /$ Cell Signaling Technology & $1: 100$ & $\mathrm{~N} / \mathrm{A}$ & $\mathrm{N} / \mathrm{A}$ \\
Complex I & Ab09798/Abcam & $\mathrm{N} / \mathrm{A}$ & $1: 1000$ & $4-98$ \\
Fox03a & $9467 /$ Cell Signaling Technology & $1: 500$ & $1: 500$ & $82: 97$ \\
NAMPT & Ab58640/Abcam & $1: 250$ & $\mathrm{~N} / \mathrm{A}$ & $\mathrm{N} / \mathrm{A}$ \\
PGC-1 $\alpha$ & NBP 104676/Novus Biologicals & $\mathrm{N} / \mathrm{A}$ & $1: 500$ & 91 \\
Sirt3 & S4072/Sigma-Aldrich & $1: 1000$ & $\mathrm{~N} / \mathrm{A}$ & $\mathrm{N} / \mathrm{A}$ \\
Sirt3 & $5490 S / C e l l$ Signaling Technology & $\mathrm{N} / \mathrm{A}$ & $1: 1000$ & 28 \\
SOD2 & NB 100-1992/NOVUS & $\mathrm{N} / \mathrm{A}$ & $1: 1000$ & 25 \\
$\beta$-Tubulin & SC-8035/Santa Cruz Biotechnology & $\mathrm{N} / \mathrm{A}$ & $1: 1000$ & 52 \\
TH & Ab23763/Abcam & $1: 2000$ & $\mathrm{~N} / \mathrm{A}$ & $\mathrm{N} / \mathrm{A}$ \\
VDAC1 & Ab14734/Abcam & $\mathrm{N} / \mathrm{A}$ & $1: 1000$ & 39 \\
\hline
\end{tabular}

N/A, Not applicable; WB, Western blot; IHC, immunohistochemistry.

Wake occurred at ZT8-ZT11, while extended sleep loss (Ext Wake) consisted of $8 \mathrm{~h}$ of continuous wake time at ZT3-ZT11 with $16 \mathrm{~h}$ intervals in the home cages after the first and second days of $8 \mathrm{~h}$ wake time. Ambient lighting, temperature, and humidity matched rested conditions. Mice were placed in a large clear plastic container supplemented with clean bedding, littermates, food, water, climbing toys, and novel nesting materials (Vankov et al., 1995; Léger et al., 2009; Gompf et al., 2010). Across trials, mice were continuously observed, and when mice were still or when the EEG (assessed in Sirt3 ${ }^{-1-}$ and SirT3wt mice) showed largeramplitude slower waveforms, new climbing toys were introduced.

Serum corticosterone assay. Upon completion of Sh Wake, Ext Wake, or Rest conditions, a subset of mice ( $n=8-14$ /group) was anesthetized with pentobarbital at ZT11. The thoracic cavity was opened, and $0.5 \mathrm{ml}$ of blood was withdrawn from the left ventricle, spun immediately, and frozen. A commercial corticosterone enzyme immunoassay (K014-H1, Arbor Assays) was used according to manufacturer's specifications to measure serum corticosterone levels (in duplicate), using a microplate reader (Versamax, Molecular Devices).

Brain tissue procurement and mitochondrial isolation. Following Rest, Sh Wake, and Ext Wake conditions, mice designated for protein $(n=$ 5-20/group) or RNA studies ( $n=5-10 /$ group) were anesthetized and transcardially perfused with ice-cold phosphobuffered saline solution with RNase inhibitor. Brains were rapidly removed and sectioned coronally for tissue punches $\left(1 \mathrm{~mm}^{3}\right)$ of LC bilaterally and stored at $-70^{\circ} \mathrm{C}$. Mitochondria isolation and cytosolic fractionation were performed using a commercial mitochondria isolation kit (catalog \#89801, Thermo Scientific) according to manufacturer's recommendations using dounce homogenization. Mitochondria-enriched samples were verified with a mitochondrial-specific protein, voltage-dependent anion channel 1 (VDAC1).

Protein assays. SOD2, catalase, SirT3, total lysine-acetylated protein, complex I acetylation, and peroxisome proliferator-activated receptorgamma coactivator $1 \alpha$ (PGC-1 $\alpha$ ) levels in B6 and/or SirT3wt and SirT3 ${ }^{-1-}$ mice across the wake conditions ( $n=5-20$ /group) were analyzed using our previously published Western blot protocol (Panossian et al., 2011). Primary antibodies are listed in Table 1). Images were analyzed with Odyssey Application software, version 3.0.16 (LI-COR), for mean integrated densities that were normalized to $\beta$-tubulin, or VDAC1 and analyzed with one- or two-way ANOVA, Bonferroni corrected.

Quantitative real-time PCR. Quantitative real-time PCR was performed on LC punches to examine SirT3, catalase, and SOD2 transcriptional responses to short-term sleep loss in B6, SirT3 ${ }^{-1-}$, and SirT3wt mice ( $n=6-10$ /group) using recently detailed methods (Panossian et al., 2011). TaqMan primer/probe sets, designed using Primer Express 2.0.0 software, were as follows: SirT3, NM_022433 sense: GAGCCTTTTGCCAGCTTGTCT, antisense: CATCCCCTAGCTGGACCACAT, probe: TGCCCCGACTGCTCATCAATCG; SOD2, NM_013671.3 sense: CAG CGAAGCCCCTGTTTATCT, antisense: GTCATCTCTGCCAAACTTG CAA, probe: CCGCCTGCCATGAGTACCATGGAC; and catalase, NM_ 
009804.2 sense: CAGGCTCTTCTGGACAAGTACAAC, antisense: AGGCTGAGCACCGGAGTTAC, probe: CACACCTACACGCAGGCCGGC. Primer/probe sets showed excellent sensitivity (detection of $>10^{4}$ copies/sample) and threshold cycle (Ct) versus log copies linearity $\left(r^{2}>0.99\right)$.

Immunohistochemistry. Mice were anesthetized with pentobarbital for transcardial perfusion with $4 \%$ paraformaldehyde; brains were harvested, cryoprotected, and sectioned coronally $40 \mu \mathrm{m}$ for 1:6 section series (Panossian et al., 2011). Primary antibodies are detailed in Table 1. Secondary donkey anti-mouse and anti-rabbit were conjugated with Alexa Fluor probes 488, 594, or 647 (Invitrogen). Imaging was performed using a Leica DM5500B microscope or SP5/AOBS confocal microscope. For confocal image acquisition, laser intensity, exposure time, detector gain, amplifier offset, and depth of the focal plane within the section were standardized across compared sections (Panossian et al., 2011).

Dihydroethidine readily crosses the blood-brain barrier and enters neurons, where, in the presence of superoxide $\left(\mathrm{O}_{2}^{--}\right)$it converts to fluorescent dihydroethidium/ethidium (DHE; Andrews et al., 2005). Groups of B6, SirT3 ${ }^{-1-}$, and SirT3wt mice randomized to the three sleep conditions ( $n=5$ /group) were given $30 \mathrm{mg} / \mathrm{kg}$ dihydroethidine (Anaspec) intraperitoneally $3 \mathrm{~h}$ before termination of the sleep loss or rested conditions. Brains were procured and processed as above. LCns were labeled with anti-tyrosine hydroxylase $(\mathrm{TH})$ detected with Alexa Fluor 488 and were imaged with a Leica SP-5 AOBS confocal microscope using excitation $\lambda, 488 \mathrm{~nm}$, and emission $\lambda>590 \mathrm{~nm}$ for DHE imaging (Hu et al., 2006). Using a 1:6 series of midbrain and pontine sections/mouse, all TH labeled neurons within the LC were examined for DHE. Images were converted to 8 bit and analyzed for integrated density over LCns (ImageJ software), and analyzed with two-way ANOVA (genotype, sleep/wake condition). In addition to measuring integrated density, we analyzed the percentage of $\mathrm{DHE}^{+} \mathrm{TH}$ neurons in the LC nuclei bilaterally for two sections per mouse $(n=5-10$ / group) using two-way ANOVA, as above.

LC sections in two separate 1:6 series $\left(n=5\right.$, SirT3 ${ }^{-1-}$ and SirT3wt) were double labeled for TH and one of the following: catalase, SirT3, nicotinamide phosphoribosyltransferase (NAMPT), FoxO3a, cleaved caspase-3 (CC3) for Sh Wake, Ext Wake, or Rest conditions. Catalase, SirT3, NAMPT, and FOXO-3a were analyzed as 8-bit gray ImageJ integrated densities for $\mathrm{TH}^{+}$somata. The percentage of TH LCns with strong FoxO3a- or CC3-labeled nuclei was counted bilaterally for each section and averaged per mouse by a reader blinded to strain and sleep conditions. Data were analyzed with two-way ANOVA for sleep condition and genotype.

To examine the effects of Ext Wake and SirT3 on LC dendritic morphology in the rostromedial pericerulear dendritic zone, where TH neurites are predominantly LCn dendrites (Shipley et al., 1996), a set of 1:6 LC $40 \mu \mathrm{m}$ coronal sections TH-labeled with alkaline phosphatase SG (Vector Laboratories) was imaged in Rest and Ext Wake SirT3wt and SirT3 ${ }^{-1-}$ mice. Montage images of the rostromedial dendritic field bilaterally were obtained within $10 \mu \mathrm{m}$ across the $z$-axis ( $2 \mu \mathrm{m}$ guard zones) and digitized (DM 5500B, DFC425, Leica) and converted to binary images on ImageJ. A two-dimensional grid with $800 \mu \mathrm{m}^{2}$ gradations was placed across the LC and dendrites medial to LCns (ImageJ software). Two scorers, blinded to conditions, measured the total area of dendrites medial to LCns throughout the rostral caudal nucleus as the area in which at least one dendrite transected opposites sides of a gradation. The number of dendrite segments spanning each gradation per LC section was also measured. Data were averaged for each mouse and then analyzed ( $n=5$ /group) using two-way ANOVA).

LCn stereological estimate. A separate set of SirT3wt and SirT3 ${ }^{-/-}$mice was randomized to Rest and Ext Wake conditions ( $n=5$ /group) for an estimation of total LCn counts. Perfusion and cryopreservation were performed, as above, and brains were sectioned at $60 \mu \mathrm{m}$. A 1:2 rostralcaudal complete LC series of DAB-labeled TH neurons and Giemsastained sections was examined using a Nikon Eclipse 600 microscope and a Stereo Investigator workstation (MicroBrightField). An optical fractionator approach (West and Gundersen, 1990) was implemented to estimate the total number of LCns per mouse. Specifically, Giemsalabeled nuclei within either TH-labeled somata or non-TH-labeled somata $>15 \mu \mathrm{m}$ in diameter within the LC nucleus that came into focus within the counting frame (probe) were counted using a $100 \times$ oilobjective. A sampling scheme of 0.25 area sampling frequency with a thickness sampling frequency of 0.79 (allowing $2 \mu \mathrm{m}$ guard zones on either side) was used. In preliminary studies implementing wild-type rested mice, this strategy provided $>200$ counts/mouse and Gundersen coefficients of error $<0.10$. LCn counts were averaged across two counters and analyzed using two-way ANOVA for genotype and sleep condition.

$\mathrm{NAD}^{+}$measurements. Tissue $\mathrm{NAD}^{+}$levels were measured using a modified version of the cycling assay described by Graeff and Lee (2002). All reagents used in this assay were obtained from Sigma. Cortical tissue from SirT3wt and SirT3 ${ }^{-1-}$ mice exposed to Rest or Ext Wake ( $n=$ 10 /group) was weighed (15-34 mg/sample), frozen in liquid nitrogen and homogenized in $0.6 \mathrm{M}$ perchloric acid at $4^{\circ} \mathrm{C}$. Cleared acid extracts were collected after pelleting insoluble material by centrifuging for $5 \mathrm{~min}$ at maximum speed at $4^{\circ} \mathrm{C}$. Cortex (Ctx) acid extracts were diluted 1:400 in $100 \mathrm{~mm}$ phosphate buffer, $\mathrm{pH}$ 8.0. In 96-well plates, $4 \mu \mathrm{l}$ of NAD standards or of diluted tissue acid extracts were combined with $100 \mu$ lof cycling reaction reagent consisting of $2 \%$ ethanol, $100 \mu \mathrm{g} / \mathrm{ml}$ alcohol dehydrogenase, $10 \mu \mathrm{g} / \mathrm{ml}$ diaphorase, $20 \mu \mathrm{M}$ resazurin, $10 \mu \mathrm{M}$ flavin mononucleotide, $10 \mathrm{~mm}$ nicotinamide, and $0.1 \%$ BSA in $100 \mathrm{~mm}$ phosphate buffer, $\mathrm{pH}$ 8.0. The cycling reaction proceeded for 20-30 min while resorufin accumulation was measured every 5-10 $\mathrm{min}$ with excitation at $544 \mathrm{~nm}$ and the counting of emitted photons at $590 \mathrm{~nm}$. Changes in emitted photon counts were compared with an NAD standard curve spanning the range from $62.5 \mathrm{~nm}$ NAD to $1000 \mathrm{~nm}$ NAD with linearity $\left(r^{2}=0.99\right)$. Data were normalized to tissue weights, and significance was tested by Student's $t$ test.

Behavioral studies. Sleep propensity is objectively measured in humans using a multiple sleep latency test (MSLT). A murine-adapted and validated MSLT (Veasey et al., 2004) was implemented to assess sleep latency for the lights-on period (ZT7-ZT9) and the lights-off period (ZT12-ZT14), using $n=8$ mice/group. Day and night tests were separated by $2 \mathrm{~d}$. For each MSLT, mice were allowed four nap opportunities, one every $30 \mathrm{~min}$, and the time from the beginning of the nap opportunity to the first period of sleep $(>30 \mathrm{~s})$ confirmed by EEG was used as the latency for that nap. For the $10 \mathrm{~min}$ period before each 20 min nap opportunity, mice were kept awake by introducing novel objects into the cage or brushing mice gently if they fell asleep in that 10 min interval. Novel objects were retrieved at the start of the nap opportunity. The average latencies across four naps per animal were averaged per group and analyzed with one-way ANOVA. Increased sleep propensity can also be marked as a slowing in waking theta frequencies from 7 to $10 \mathrm{~Hz}$ to $5-7 \mathrm{~Hz}$ (Vyazovskiy and Tobler, 2005). We compared the percentages of theta power in the 5-7 and $7-10 \mathrm{~Hz}$ ranges in response to a clean cage across $5 \mathrm{~min}$ upon transfer to a clean cage ( $n=6$ /group) using one-way ANOVA, excluding mice with movement artifacts in the EEG signal. Total time spent in wakefulness per $24 \mathrm{~h}$, NREMS per $24 \mathrm{~h}$, and REMS per $24 \mathrm{~h}$, and the bout lengths for each behavioral state averaged across the $24 \mathrm{~h}$ period were also measured and analyzed for genotype effects using one-way ANOVA with Bonferroni correction ( $n=8-10 /$ group).

LCn lesions impair NREM sleep homeostasis, as measured by a less steep decline in slow-wave EEG power in NREM sleep across the rest-predominant lights-on period and as the magnitude of slowwave EEG power rise after a $6 \mathrm{~h}$ sleep loss exposure in the lights-on period (Cirelli et al., 2005). To assess NREMS homeostasis, mice were maintained awake (home cages) for $6 \mathrm{~h}$ (ZT1-ZT6) with EEG/EMG confirmation, followed by a $6 \mathrm{~h}$ recovery sleep. The relative delta (delta/total power for each hour normalized to the delta power/total power of the last hour of the lights-on period) was measured for the $12 \mathrm{~h}$ baseline lights-on period and the $6 \mathrm{~h}$ recovery after $6 \mathrm{~h}$ sleep loss, with each interval examined for frequency distribution of EEG waveforms $/ 0.25 \mathrm{~Hz}$ bins ( $n=6 \mathrm{mice} /$ group). Data were analyzed using two-way ANOVA for genotype and sleep condition. 
A

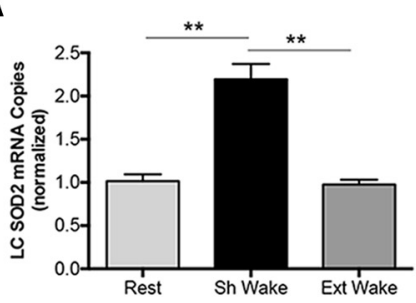

D

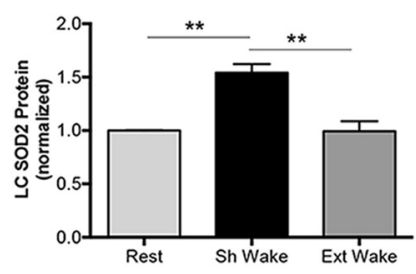

G

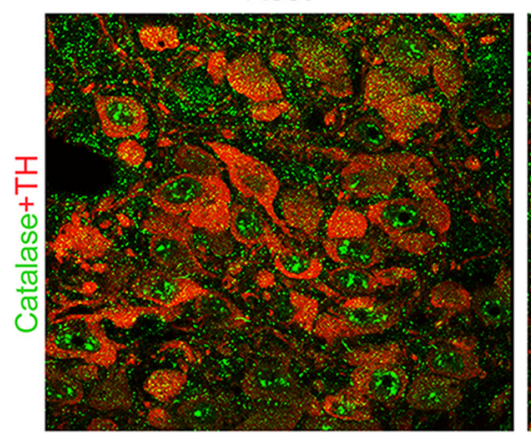

B

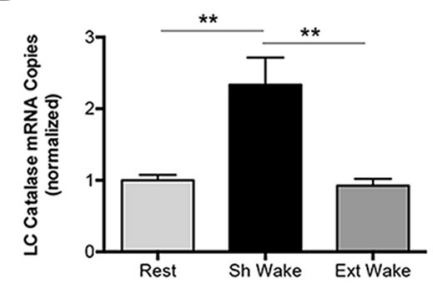

E

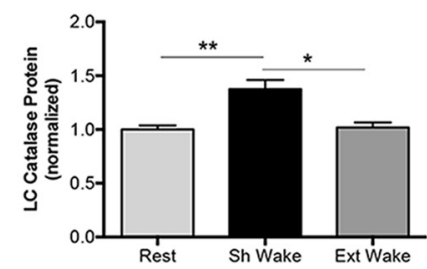

C

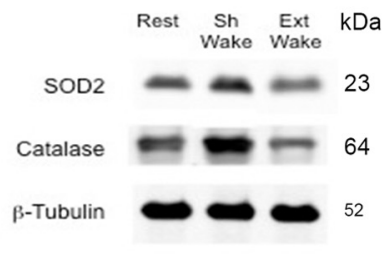

$\mathbf{F}$

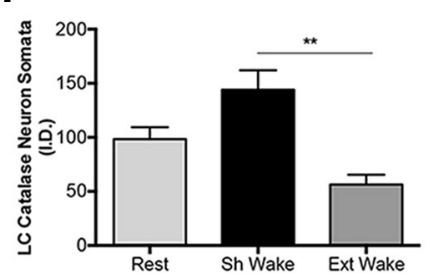

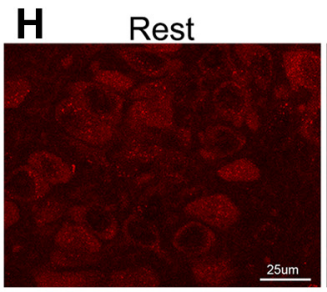
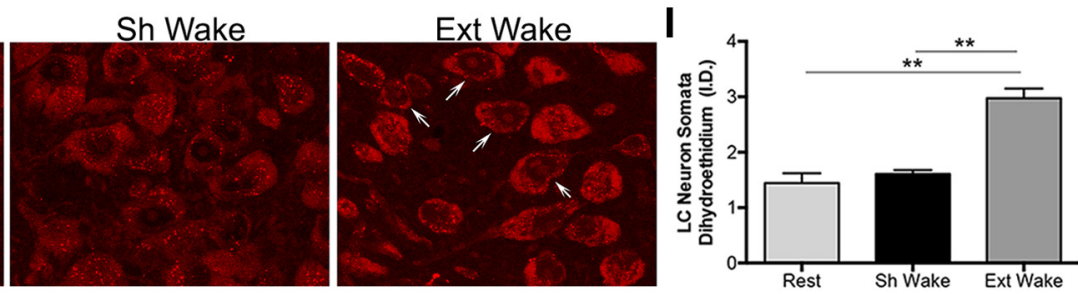

Figure 1. Redox responses in the LCns diverge in response to short-term and extended wakefulness. $A$, SOD2 mRNA copy numbers, normalized to 185 RNA copy number and to the Rest value. Shown are the mean \pm SE values for Rest (light gray), $3 \mathrm{~h}$ short-term sleep loss (Sh Wake, black), and sleep loss extended to $8 \mathrm{~h} / \mathrm{d}$ for 3 consecutive days (Ext Wake, dark gray; $n=6-10 / g r o u p$ ). Lines denote significant differences across groups by one-way ANOVA, Bonferroni corrected. ${ }^{* *} p<0.01$. B, Catalase mRNA copy numbers, normalized and analyzed similarly for the same groups ( $n=6$-10/group). ${ }^{* *} p<0.01$. C, Representative LC protein immunoblots for S0D2, catalase, and corresponding $\beta$-tubulin for Rest, Sh Wake, and Ext Wake conditions. D, E, SOD2 (D) and catalase (E) LC protein responses across Rest, Sh Wake, and Ext Wake ( $n=8-10 /$ group), normalized to $\beta$-tubulin and mean rested condition value, analyzed with one-way ANOVA, Bonferroni corrected. ${ }^{*} p<0.05 ;{ }^{* *} p<0.01$. $\boldsymbol{F}$, Mean \pm SE integrated density of catalase immunofluorescent intensity within LCns across Rest, Sh Wake, and Ext Wake conditions ( $n=5 /$ group). ${ }^{*} p<0.01 . \mathbf{G}$, Representative confocal images at mid-LC. TH (red) delineates LCns. Catalase (green) is present largely in nuclei of LCns, particularly in response to Sh Wake. Scale bar, $25 \mu \mathrm{m}$. $\boldsymbol{H}$, Mid-LC nucleus confocal images $(1 \mu \mathrm{m})$ of autofluorescence (excitation and emission, $488 \mathrm{and}>590 \mathrm{~nm}$ ) from oxidized DHE for detection of $0_{2}^{-*}$ in representative LC sections from Rest, Sh Wake, and Ext Wake mice. Arrows highlight LCns with nuclear/nucleolar DHE-autofluorescent labeling. Scale bar, $25 \mu \mathrm{m}$. I, Group DHE-integrated density (mean \pm SE) signal for LCns ( $n=5 /$ group), one-way ANOVA. ${ }^{* *} p<0.01$.

\section{Results}

Divergent redox responses in the LC occur following Sh Wake and Ext Wake

In response to Sh Wake, SOD2 mRNA in LC increased $(t=$ 8.2, $p<0.01$; Fig. $1 A)$, as did catalase mRNA $(t=5.2, p<0.01$; Fig. $1 B$ ). In contrast, in response to Ext Wake, antioxidant enzyme mRNA levels in LC were unchanged relative to rested conditions (SOD2, $t=0.3$; catalase, $t=0.3$, NS; Fig. $1 A, B$ ). Consequently, both SOD2 and catalase LC mRNA copy numbers were higher in Sh Wake than in Ext Wake $(t=5.3, p<$ 0.01 ; and $t=4.1, p<0.01$, respectively). Similar wake duration-dependent responses were observed for SOD2 and catalase protein, where LC micropunch SOD2 and catalase protein (normalized to $\beta$-tubulin and mean rested values) increased in Sh Wake $(t=4.8, p<0.01$; and $t=6.0, p<0.01$, respectively; Fig. $1 C-E)$, yet in response to Ext Wake neither SOD2 nor catalase changed $(t=0.3, t=0.2$, respectively; Fig. $1 C-E)$. Antioxidant proteins were increased in LC tissue punches of Sh Wake mice, relative to Ext Wake mice, for both SOD2 $(t=5.4, p<0.01)$ and catalase $(t=4.1, p<0.05)$. Immunofluorescence was used to localize the catalase response within the LC nucleus across the sleep conditions. Under Rest and Sh Wake conditions, catalase labeling was prominent in LCns, particularly in LCn nuclei (Fig. $1 F, G$ ) as 
A

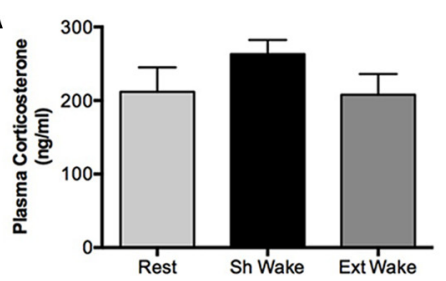

D

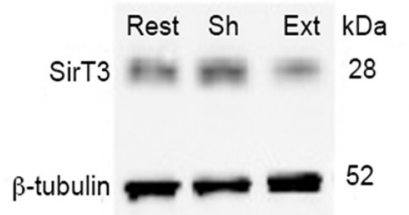

F

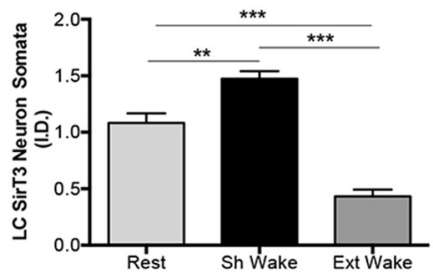

B

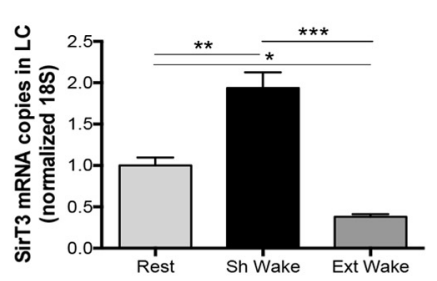

E
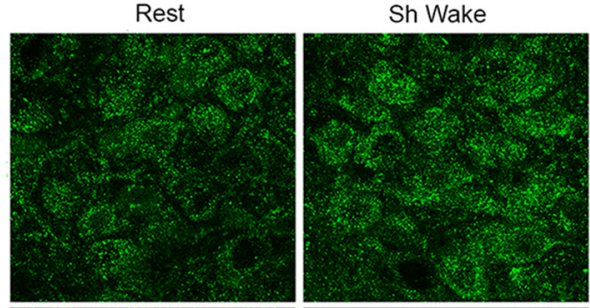

C

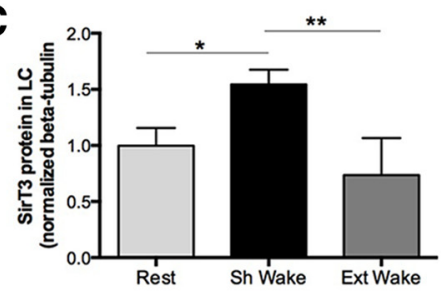

Ext Wake

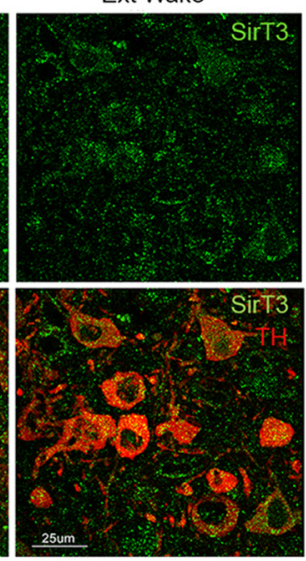

Figure 2. SirT3 responses in LC vary with sleep loss duration, while corticosterone is not affected. $A$, Plasma corticosterone levels at ZT11 in mice exposed to Rest, Sh Wake, and Ext Wake conditions ( $n=8-14 /$ group). No significant differences were observed with one-way ANOVA despite $94 \%$ statistical power to detect an increase of $100 \mathrm{ng} / \mathrm{ml}$. $\boldsymbol{B}$, Mean \pm SE LC SirT3 mRNA copies, normalized to 18S RNA and mean Rest values for Rest, Sh Wake, and Ext Wake conditions ( $n=8-10 /$ group) were analyzed with one-way ANONA, Bonferroni corrected. Bars highlight group differences: * $p<$ $0.05 ;{ }^{* *} p<0.01 ;{ }^{* * *} p<0.001$. C, LCSirT3 protein for Rest, Sh Wake, and Ext Wake conditions ( $n=8-10 /$ group) normalized to $\beta$-tubulin and mean Rest values are presented as mean \pm SE. Data were analyzed with one-way ANOVA: ${ }^{*} p<0.05 ;{ }^{* *} p<0.01$. D, Representative Western blots for LC SirT3 across the three conditions and loading control. $\boldsymbol{E}$, Representative LC images across wake conditions (Rest, Sh Wake, and Ext Wake) showing SirT3 (green) alone in the top and SirT3 (green) with tyrosine hydroxylase (red) delineating LCns in the bottom. Scale bar, $25 \mu \mathrm{m}$. F, Summary data, mean \pm SE, for SirT3 confocal integrated densities in LCns ( $n=5 /$ group). ${ }^{* *} p<0.01 ;{ }^{* * *} p<0.001$.

well as in nearby medial and lateral parabrachial neurons and neurons within Barrington's nucleus (data not shown). LCn catalase immunoreactivity relative to Rest conditions was not different for either Sh Wake or Ext Wake mice, yet was higher in Sh Wake relative to Ext Wake LCns $(t=4.7, p<0.01)$. Thus, Sh Wake results in a robust increase in SOD2 and catalase in the LC that is not evident under conditions of Ext Wake.

In light of the discordant redox responses across Sh Wake and Ext Wake, we examined the effects of wake duration on $\mathrm{O}_{2}^{-\cdot}$ availability within LCns. There was no effect of Sh Wake, relative to Rest, on DHE signal intensity in $\mathrm{LCn}(t=0.8$, NS; Fig. $1 H, I)$. In contrast, $\mathrm{O}_{2}^{-\cdot}$ within LCn soma increased in mice exposed to Ext Wake, relative to Rest $(t=7.4, p<0.001)$ and increased within the LCn nuclei of Ext Wake mice [Rest, $1.5 \pm 0.1$ inner diameter (i.d.) vs Ext Wake mice, $2.4 \pm 0.1$ i.d.; $t=6.1, p<0.0001]$. In summary, redox homeostasis is maintained in LCns across Sh Wake, while Ext Wake results in LCn oxidative stress.

\section{Sh Wake and Ext Wake have minimal effects on plasma} corticosterone levels

Corticosterone levels (B6, $n=8-14$ /group) were unchanged across groups, as summarized in Figure $2 A$. The dataset had $82 \%$ power to detect a difference of $50 \mathrm{ng} / \mathrm{ml}$ and $94 \%$ power to detect an increase of $100 \mathrm{ng} / \mathrm{ml}$ corticosterone relative to Rest. Thus, the paradigms used (Sh Wake and Ext Wake) are not associated with a significant increase in plasma corticosterone levels.
SirT3 responses in LC diverge with wake duration

Relative to Rest conditions, SirT3 mRNA copies increased in the LC nucleus in response to Sh Wake $(t=5.3, p<0.01$; Fig. $2 B)$ and fell in mice exposed to Ext Wake $(t=3.5, p<0.05$; Fig. $2 B)$. Consequently, LC SirT3 mRNA was much higher in Sh Wake than in Ext Wake mice $(t=8.9, p<0.001)$. A similar wake duration-dependent effect was observed for SirT3 protein. SirT3 protein in LC micropunches increased in response to Sh Wake $(t=3.1, p<0.05)$, yet was unchanged with Ext Wake, relative to Rest $(t=1.8$, NS), so that LC SirT3 protein was higher in Sh Wake relative to Ext Wake $(t=5.6, p<0.01$; Fig. $2 C, D)$. To determine whether SirT3 responses observed in the LC nucleus varied within LCns, we examined SirT3 immunoreactivity in THlabeled LCns. SirT3 immunoreactivity increased in Sh Wake LCn relative to Rest $(t=3.5, p<0.01)$ and declined in Ext Wake LCns relative to both Rest $(t=6.6, p<0.001)$ and to Sh Wake $(9.4, p<$ 0.001; Fig. $2 E, F)$.

To determine whether the reduced SirT3 protein translates into reduced Sirt3 activity in Ext Wake, we examined LC mitochondrial lysine acetylation as an index of SirT3 activity ( $\mathrm{He}$ et al., 2012). No differences in LC mitochondrial acetylation in SirT3wt mice were observed between Rest and Sh Wake conditions ( $t=0.02$, NS; Fig. $3 A, B)$. Mitochondrial acetylation in the LC of SirT3wt mice, however, was increased in Ext Wake relative to Rest $(t=3.5, p<0.01)$ and to Sh Wake $(t=3.4, p<$ $0.01)$, while cytoplasmic acetylation was unchanged $(t=0.4-$ 1.0, NS) across all comparisons (Fig. $3 A, C$ ). While both mitochondrial and cytosolic isolates showed a prominent band at $53-56 \mathrm{kDa}$, only mitochondrial isolates showed a second band 
A

\section{SirT3 wt LC}

B

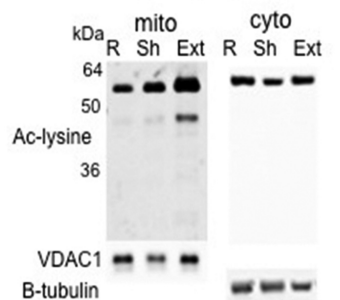

D IP: Complex I WB: Acetyl-Lys $\mathrm{kDa}$ 64-

36-

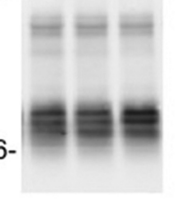

R Sh Ext
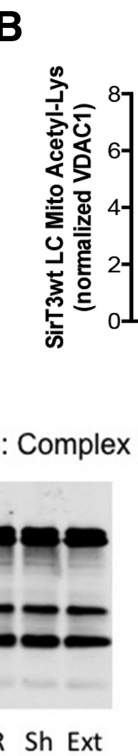

C

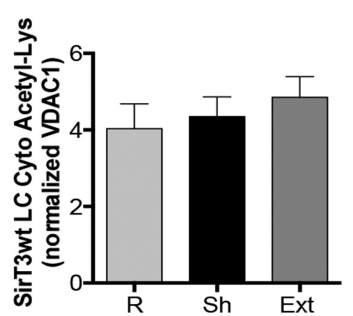

E

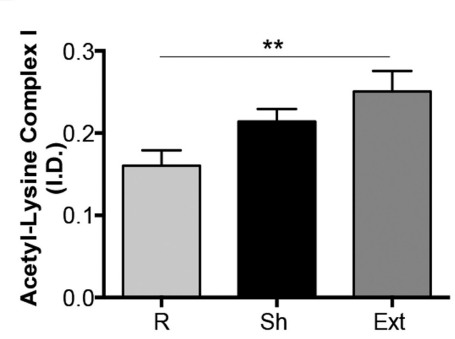

F

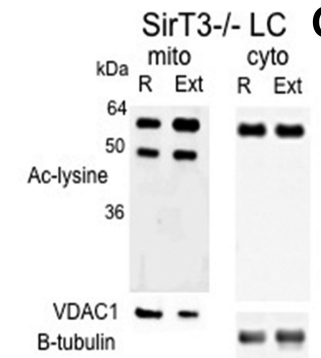

I

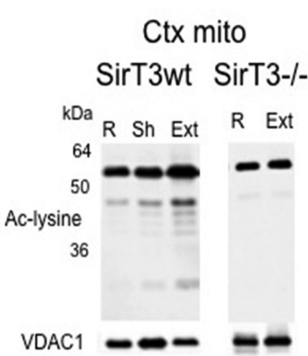

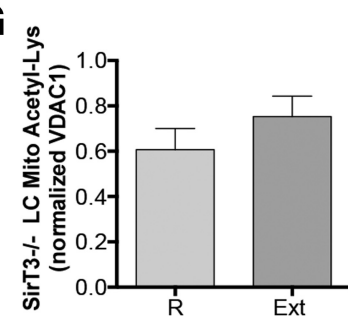

$\mathrm{H}$
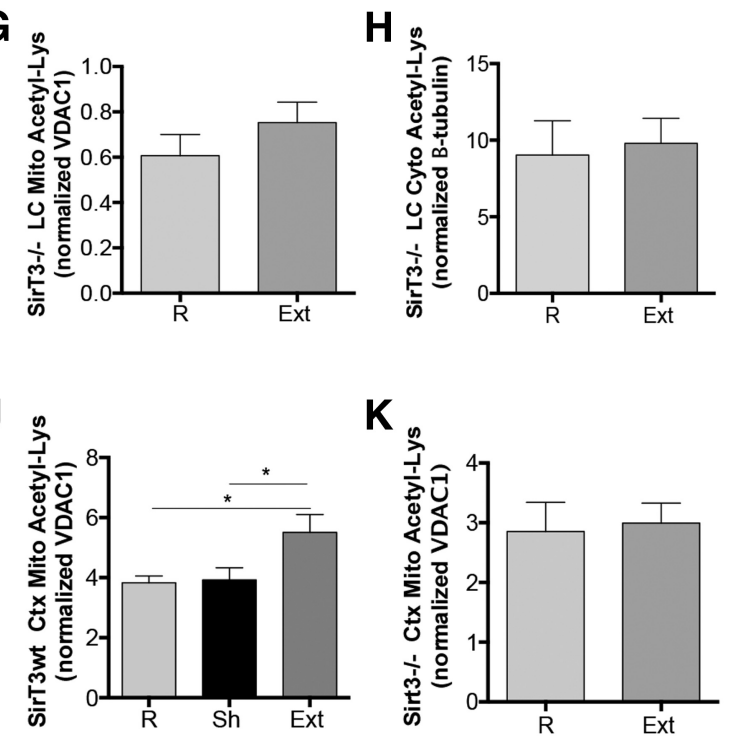

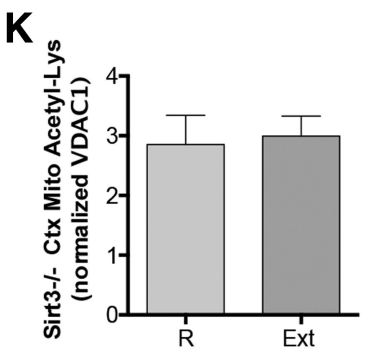

Figure 3. Mitochondrial lysine acetylation varies with wake duration and SirT3. $A$, Representative immunoblots of LC lysineacetylated proteins and loading controls (VDAC1 and tubulin) in mitochondrial (mito) and cytoplasmic (cyto) enriched samples from SirT3wt mice exposed to Rest (R), Sh Wake (Sh), and Ext Wake (Ext) conditions. B, Summary data (mean \pm SE) integrated densities for LC mitochondrial isolate-acetylated protein normalized to VDAC1 for the three conditions in SirT3wt LC samples $(n=$ 20/group). One-way ANOVA identified significant differences. ${ }^{* *} p<0.01$. C, Mean \pm SE integrated densities for LC cytoplasmic isolate-acetylated protein normalized to $\beta$-tubulin for the same conditions ( $n=20 /$ group). $\boldsymbol{D}$, Representative Western blots of SirT3wt LC mitochondrial isolate acetyl-lysine on immunoprecipitate of complex I proteins (left) and complex I protein loading controls used in normalization (right). $\boldsymbol{E}$, Mean \pm SE normalized integrated densities for acetyl (Ac)-lysine (Lys) on complex I immunoprecipitates from mitochondria across the three wake conditions ( $n=10 /$ group). ${ }^{* *} p<0.01$. $\boldsymbol{F}$, Representative immunoblots of LC lysine-acetylated proteins and loading controls (VDAC1 and tubulin) in mitochondrial (mito) and cytoplasmic (cyto) enriched samples from SirT3 ${ }^{-1-}$ mice exposed to Rest and Ext Wake (Ext) conditions. G, Mean \pm SE integrated densities for $\mathrm{SirT3}^{-1-} \mathrm{LC}$ mitochondrial isolate-acetylated protein normalized to VDAC1 for the two conditions ( $n=20 /$ group), with nonsignificant differences across wake conditions. $\boldsymbol{H}$, Mean \pm SE integrated densities for SirT3 ${ }^{-1-}$ LC cytoplasmic isolate-acetylated protein normalized to $\beta$-tubulin for the same conditions ( $n=20 /$ group). I, Immunoblot examples for Ctx lysine-acetylated proteins and loading control (VDAC1) in mito samples in SirT3wt (left) and SirT3 ${ }^{-1-}$ (right) mice exposed to Rest, Sh Wake (Sh), and Ext Wake (Ext) conditions. J, $\boldsymbol{K}$, Summary (mean \pm SE) normalized integrated densities for LC mitochondrial isolate-acetylated protein normalized to VDAC1 for SirT3wt $(\boldsymbol{J})$ and $\operatorname{SirT3}{ }^{-/-}(\boldsymbol{K})$ mice, analyzed with one-way ANOVA. * $p<0.05$.

at $46-49 \mathrm{kDa}$. Mitochondrial ETC protein complex I acetylation did not vary between Rest and Sh Wake $(t=2.5$, NS), yet increased in Ext Wake relative to Rest $(t=4.0, p<0.01$; Fig. $3 D$ ). To determine whether the Ext Wake LC mitochondrial protein acetylation responses observed occurred independent of Sirt3, we examined LC mitochondrial and cytosolic protein acetylation responses to Ext Wake in the SirT3 ${ }^{-1-}$ mice. LC mitochondrial protein acetylation did not increase in response to Ext Wake in SirT3 ${ }^{-1-}$ mice $(t=0.2$, NS; Fig. $3 F)$. A second prominent band at 46-49 kDa was evident in all Rest and Ext wake SirT3 ${ }^{-1-}$ mice. As with SirT3wt mice, cytoplasmic protein acetylation did not change in response to Ext Wake ( $t=0.3$, NS). We next explored whether the mitochondrial protein acetylation response to Ext Wake is specific to the LC or whether this also occurs in the frontal Ctx, examining both SirT3wt and SirT3 ${ }^{-1-}$ mice. As observed with the LC, mitochondrial lysine acetylation in the Ctx increased significantly in response to Ext Wake, relative to Rest $(t=2.9, p<0.05)$ and to Sh Wake $(t=2.6, p<0.05$; Fig. $3 I, J)$. In mitochondrial isolates of the Ctx, prominent bands occurred at the same kilodalton level as in the LC, but also showed acetylation of proteins of smaller molecular weights in all mice exposed to Ext wake and a few mice exposed to Sh wake (Fig. 3I). As observed in the LC, there was no effect of Ext Wake on mitochondrial lysine acetylation in Ctx punches from SirT3 ${ }^{-1-}$ mice $(t=0.2$, NS; Fig. $3 I, K)$. Thus, sleep loss results in duration- and SirT3dependent mitochondrial lysine acetylation responses in both the $\mathrm{LC}$ and Ctx.

Reduced SirT3 activity could be explained by reduced SirT3 protein, but also by reduced levels of $\mathrm{NAD}^{+}$. Thus, we next examined whether the rate-limiting enzyme for $\mathrm{NAD}^{+}$synthesis for sirtuins, NAMPT, also changed in response to sleep loss. We found that NAMPT immunoreactivity in LCns increased in Sh Wake, relative to both Rest $(t=3.1, p<$ 0.05) and Ext Wake $(t=3.3, p<0.05$; Figs. $4 A, B)$. We then measured actual $\mathrm{NAD}^{+}$levels in cortical tissue, where tissue was sufficiently abundant and where a similar acetylation response to Ext Wake was observed as in the LC. Surprisingly, in SirT3 wt mice, cortical NAD ${ }^{+}$increased in response to Ext Wake, relative to Rest $(t=$ $5.8, p<0.01$; Fig. $4 C$ ), and was far higher in Rest SirT3 ${ }^{-1-}$ mice than in Rest SirT3wt mice $(t=7.3, p<0.001)$. NAD ${ }^{+}$ levels did not change in SirT3 ${ }^{-1-}$ mice in response to Ext Wake $(t=1.8$, NS). Thus, mitochondrial protein acetylation in response to Ext Wake, is most likely attributable to the loss of SirT3 activity rather than a reduction in total NAD ${ }^{+}$, and SirT3 deficiency is associated with marked increases in total $\mathrm{NAD}^{+}$. 
The redox response to Sh Wake requires SirT3

We next sought to determine whether SirT3 was essential for the antioxidant response to Sh Wake and whether loss of SirT3 would increase $\mathrm{O}_{2}^{-\cdot}$ in $\mathrm{LCn}$ upon exposure to Sh Wake. All SirT3 ${ }^{-1-}$ and SirT3wt mice maintained wakefulness across $>95 \%$ of the Sh Wake exposure. Across Rest conditions, SOD2 mRNA copy numbers ( $n=6-8$ /group) did not vary with SirT3 genotype $(t=1.1$, NS; Fig. $5 A)$. As with B6 mice above, SirT3wt mice exposed to Sh Wake showed increased LC SOD2 mRNA, relative to Rest $(t=4.1$, $p<0.01)$, and increased catalase mRNA $(t=4.1, p<0.01$; Fig. $5 B)$. In contrast, in SirT $3^{-1-}$ mice, SOD 2 and catalase mRNA did not increase in response to Sh Wake (SOD2, $t=0.05$; catalase, $t=0.7$; NS). SirT3wt mice had increased LC SOD2 protein in Sh Wake relative to Rest $(t=$ 2.7, $p<0.05$; Fig. 5C,D). In contrast, SirT3 $^{-1-}$ mice showed no difference in LC SOD2 protein between Rest and Sh Wake $(t=1.8$, NS). Thus, SirT3 has a minimal effect on basal antioxidant enzyme levels but is essential for the LC antioxidant responses to Sh Wake.

We then examined the role of SirT3 in the $\mathrm{O}_{2}^{-}$response to Sh Wake in LCns. The LCn DHE signal did not differ with SirT3 genotype across Rest conditions $(t=1.1$, NS), and, as with B6 mice, SirT3wt mice did not show a difference in $\mathrm{O}_{2}^{-\cdot}$ between Rest and Sh Wake conditions $(t=0.03$, NS; Fig. $5 E-G)$. There was no genotype effect in the percentage of LCns with DHE labeling for Rest conditions ( $t=1.1$, NS; Fig. $5 F)$, and there was no increase in the percentage of DHE-labeled LCns in SirT3wt mice from rested to short-term sleep loss conditions $(t=0.9$, NS). There was, however, a large increase in the percentage of DHE-positive LCns in SirT3 ${ }^{-1-}$ mice from Rest to Sh Wake $(t=10.9, p<0.0001)$, and there was a large increase in the percentage of DHE-positive LCns in SirT3 ${ }^{-1-}$ sleep loss compared with that in SirT3wt mice with 3 h of wakefulness $(t=6.9, p<0.0001)$. Similarly, SirT3 ${ }^{-1-}$ mice showed increased $\mathrm{O}_{2}^{-\cdot}$ signal intensity in LCns in Sh Wake relative to Rest mice $(t=4.4, p<0.001)$, and the $\mathrm{O}_{2}^{-}$signal response to Sh Wake in SirT3 ${ }^{-1-}$ mice, then, was significantly higher than in SirT3wt mice $(t=2.9, p<0.05)$. Thus, in response to Sh Wake, SirT3 is essential for the maintenance of redox homeostasis in LCns.

\section{SirT3 deficiency reduces nuclear FoxO3 and prevents} upregulation of PGC-1 $\alpha$ in Sh Wake

SirT3 is predominantly a mitochondrial protein; thus, the dependency on SirT3 for the increased SOD2 and catalase mRNA observed in response to Sh Wake implies a mitochondria-tonucleus communication. SirT3 has been shown to activate Foxo3a under conditions of physiological stress (Sundaresan et al., 2009; Tseng et al., 2013), and transcription of both SOD2 and catalase are dependent upon Foxo3a activation and nuclear translocation (Kops et al., 2002). Thus, we next examined whether Foxo3a in LCns translocates to LCn nuclei in response to Sh Wake and Ext Wake, and whether this response requires SirT3. The percentage of LCns with strong nuclear FoxO3a labeling did not increase with Sh Wake $(t=3.3$, NS) or with Ext Wake $(t=0.2$, NS; Fig. $6 A, B)$. For rested conditions, there was no genotype effect on the percentage of nuclear Fox3a in LCns $(t=$ $1.8, \mathrm{NS})$ or for Ext Wake ( $t=3.8$, NS). In contrast, under conditions of Sh Wake, there was a strong genotype effect on the percentage of FoxO3a-labeled LCn nuclei $(t=7.4, p<0.001)$. Similarly, in SirT3wt mice, the nuclear Foxo3a signal increased in Sh Wake mice relative to Rest mice $(t=3.6, p<0.05)$ and was increased in SirT3wt Sh Wake relative to SirT3 ${ }^{-1-}$ Sh Wake mice $(t=9.0, p<0.0001$; Fig. $6 A-C)$. In contrast, Sh Wake did not influence nuclear Foxo3a in SirT3 ${ }^{-1-}$ mice. Neither SirT3 ${ }^{-1-}$ nor SirT3wt mice showed a Foxo3a response to Ext Wake. The capacity of Foxo3a to regulate antioxidant genes is dependent upon PGC-1 $\alpha$ (Olmos et al., 2009). Therefore, we measured PGC- $1 \alpha$ protein in LC punches across the three wake conditions and two genotypes, again finding an upregulation in Sh Wake dependent on SirT3. Specifically, in SirT3wt mice, PGC-1 $\alpha$ increased in the LC in response to Sh Wake $(t=3.1, p<0.05)$, but not in response to Ext Wake $(t=0.2$, NS; Fig. $6 D, E)$, while in 
A

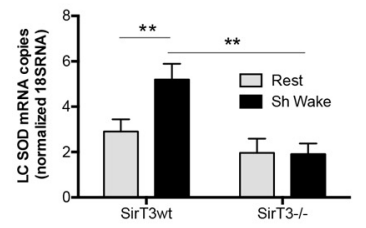

D

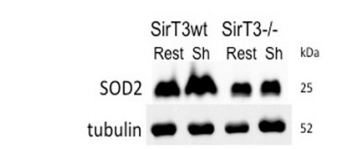

$\mathbf{F}$

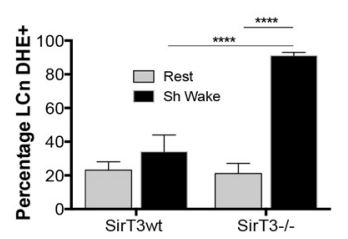

G

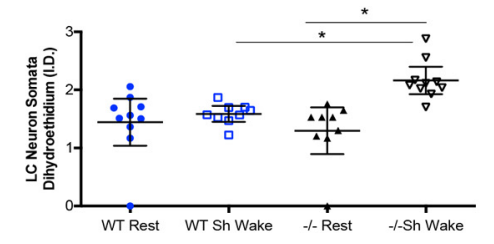

Figure 5. SirT3 is essential for the Sh Wake antioxidant response and redox homeostasis in LCns. $A$, Mean \pm SELCSOD2 mRNA copies, normalized to $18 \mathrm{~S}$ RNA for Rest (gray) and Sh Wake (black) conditions in SirT3wt and SirT3 ${ }^{-1-}$ mice ( $n=8-10 /$ group). Data were analyzed with two-way ANOVA, Bonferroni corrected: ${ }^{*} p<0.05 ;{ }^{* *} p<0.01$. B, Mean \pm SELC catalase mRNA copies, normalized to 18S RNA for Rest (gray) and Sh Wake (black) conditions in SirT3wt and SirT3 ${ }^{-1-}$ mice $\left(n=8-10 /\right.$ group). ${ }^{* *} p<$ 0.01. C, LC SOD2 protein for Rest (gray) and Sh Wake (black) conditions in SirT3wt and SirT3 ${ }^{-1-}$ mice ( $n=8-10 /$ group). ${ }^{* *} p<$ 0.01. D, Typical LC nucleus immunoblots for SOD2 and loading control tubulin for SirT3wt and SirT3 ${ }^{-1-}$ mice across Rest and Sh Wake (Sh) conditions. $\boldsymbol{E}$, Confocal images of DHE autofluorescence in SirT3wt and SirT3 ${ }^{-1-}$ mice across Rest and Sh Wake conditions. Scale bar, $25 \mu \mathrm{m}$. Arrows highlight nuclei/nucleolar ox-DHE labeling. $F$, Mean \pm SE percentages of LCns with DHE labeling for SirT3wt and SirT3 ${ }^{-1-}$ mice across Rest and Sh Wake conditions ( $n=10 /$ group). Data were analyzed with two-way ANOVA. ${ }^{* * *} p<0.0001$. G, Scattergrams of individual data for confocal autofluorescence integrated density over LCns across the four groups ( $n=10$ /group) with mean and $95 \%$ confidence interval bars. Data were analyzed with two-way ANOVA; bars delineate ${ }^{*} p<0.05$.

SirT3 ${ }^{-1-}$ mice, PGC- $1 \alpha$ was unchanged in both Sh Wake $(t=$ 0.8 , NS) and in Ext Wake $(t=0.8$, NS). Consequently, LC PGC- $1 \alpha$ was higher in SirT3wt mice than in SirT3 ${ }^{-1-}$ mice under conditions of Sh Wake $(t=3.5, p<0.05)$. In summary, in response to Sh Wake, SirT3 is essential for the maintenance of LC nuclear Foxo3a and for upregulation of PGC- $1 \alpha$ in the LC.

\section{Ext Wake promotes LCn dendritic pruning, neurodegeneration, and apoptosis}

In light of the reduced SirT3 level in Ext Wake, we next explored whether Ext Wake injures LCns by examining LCn dendrite area, neuron counts, and caspase- 3 activation. There was a pronounced genotype effect on the LCn dendritic field across Rest conditions, in that SirT3wt mice showed far greater dendritic segments than SirT3 ${ }^{-1-}$ mice $(t=7.4, p<0.0001$; Fig. $7 A, B)$. In SirT3wt mice, LCn dendritic segments were reduced in Ext Wake, relative to Rest $(t=6.6, p<0.001$; Fig. $7 A, B)$. In SirT3 ${ }^{-1-}$ mice, there was no further reduction in dendritic segments with Ext Wake $(t=1.7, \mathrm{NS})$. Ext Wake did, however, influence dendritic morphology in that dendrites in SirT3 ${ }^{-1-}$ mice exposed to Ext Wake evidence pronounced beading and vacuolization, as illustrated in Figure 7A. Qualitatively, $\mathrm{TH}$ labeling of LCns appeared equally strong across all four groups.
For stereological counts, LCns were identified in seven to eight sections/mouse. Across mice, the number of sampling sites varied from 369 to 637 , and the total number of markers counted per mouse varied from 115 to 353 . Very few non-TH-labeled neurons ( $0-4$ neurons per mouse) with diameters $>15 \mu \mathrm{m}$ were identified within the LC nucleus in any of the groups. In all mice, the Gundersen coefficient of error was $<0.10$ and averaged 0.08 for each group. Effects of Ext Wake on total (bilateral, complete nucleus) LCn cell counts were remarkably similar to those observed for LCn dendritic fields. Specifically, SirT3wt mice exposed to Ext Wake, relative to Rest, showed reduced LCn counts $(t=5.1, p<0.05$; Fig. $7 C)$. Across Rest conditions, SirT3 ${ }^{-1-}$ mice had fewer LCns than SirT3wt mice $(t=6.9, p<$ 0.001 ) and showed no reduction in LCn count in response to Ext Wake (1.6, NS). Nuclear CC3 in LCns increased in SirT3wt mice in Ext Wake $(t=5.6, p<0.01)$. In contrast, SirT3 ${ }^{-1-}$ mice did not show an increase in LCn CC3 in response to Ext Wake, relative to Rest ( $t=3.0$, NS; Fig. $7 D, E)$. Thus, Ext Wake imparts significant injury including neuronal loss and activation of caspase-3 in LCns in wild-type mice, while mice lacking SirT3 evidence a baseline reduction in LCns and dendrites, and develop marked dendritic dystrophy upon Ext Wake.

\section{Absence of SirT3 impairs wakefulness, LC c-fos activation response to novel environment, and sleep homeostasis} There were overall genotype and time-oftest effects on the mean sleep latencies in the MSLT $(p<0.001)$. In SirT3wt mice, sleep latency was increased in the lightsoff period relative to the lights-on test period $(t=3.4, p<0.05$; Fig. $8 A$ ). In contrast, SirT3 ${ }^{-1-}$ mice did not show a longer sleep latency for the lights-off period ( $t=0.7, \mathrm{NS})$. There was no effect of genotype for the lights-on MSLT ( $t=1.4$, NS); a genotype effect, however, was observed for the lights-off MSLT $(t=4.3$, $p<0.01$ ). Thus, SirT3 ${ }^{-1-}$ mice show objective sleepiness in the lights-off (active) period.

A second measure of wakefulness is theta frequency in response to environmental change, where higher-frequency theta waveforms are anticipated. SirT3wt mice showed increased fast theta, relative to $5-7 \mathrm{~Hz}$ theta $(t=5.8, p<0.01)$, while SirT3 ${ }^{-1-}$ mice showed a balance of slow and fast theta waveforms $(t=2.6$, NS). Relative to SirT3wt mice, SirT3 ${ }^{-1-}$ mice showed a higher percentage of theta power at the slower theta frequencies $(5-7 \mathrm{~Hz}$; $54 \pm 3 \%$ vs $40 \pm 1 \% ; t=4.1, p<0.01)$ and less relative theta power for higher frequencies $(7-10 \mathrm{~Hz} ; 45 \pm 3$ vs $59 \pm 5 ; t=4.2$, $p<0.01$; Fig. $8 B$ ). Thus, mice deficient in SirT3 have impaired theta responses to an environmental change.

There were no genotype differences in either mean $24 \mathrm{~h}$ sleep/ wake times or mean bout lengths, as summarized in Figure 8, $C$ and $D$. Specifically, total wake time per $24 \mathrm{~h}$ period and average wake bout length did not differ across SirT3 ${ }^{-1-}$ and SirT3wt 
A
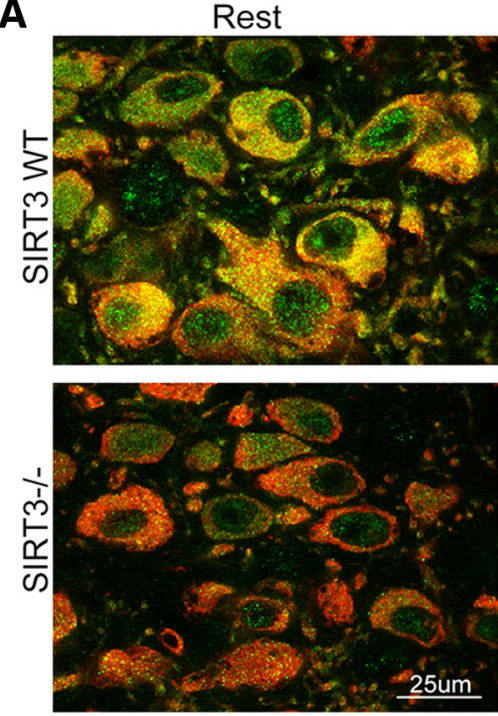

B

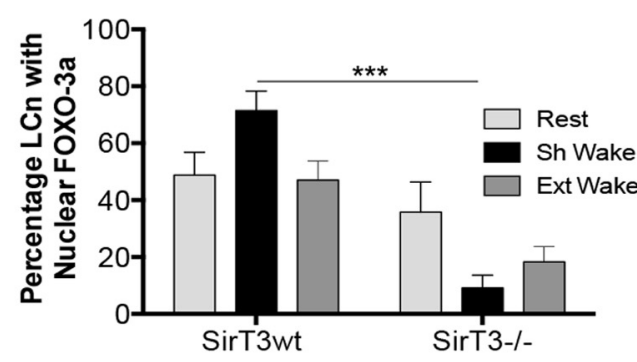

D

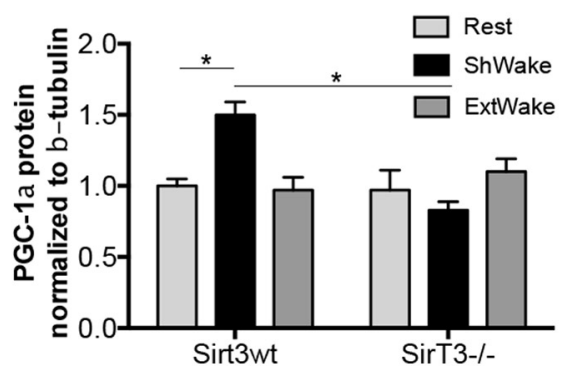

Sh Wake
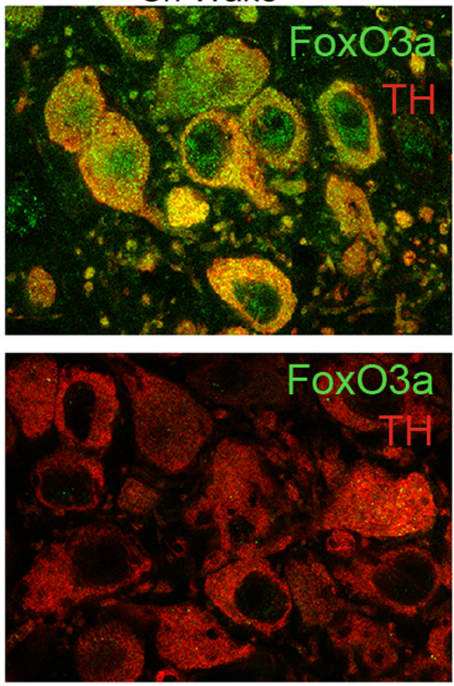

Ext Wake
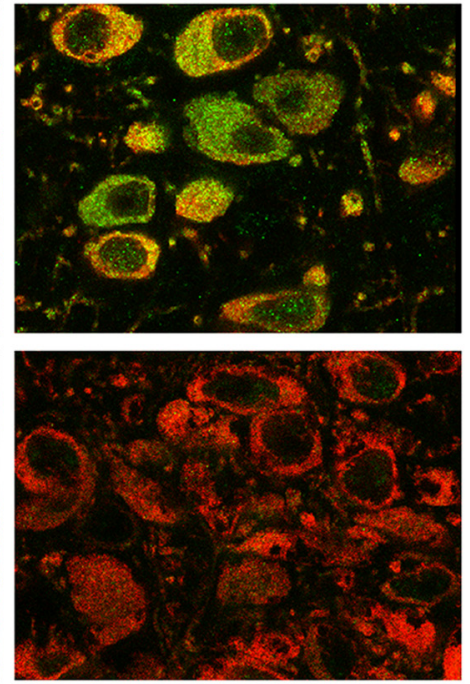

C

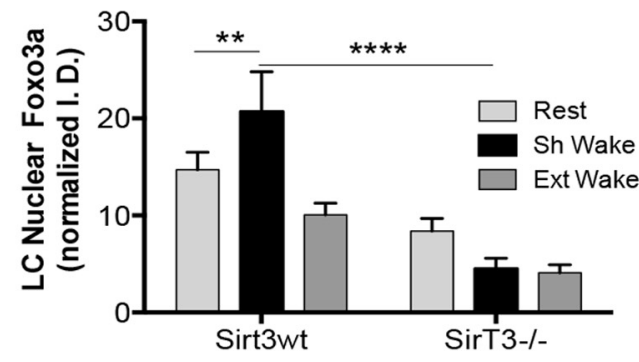

E

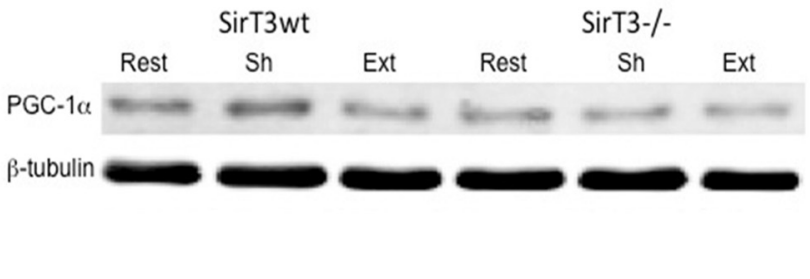

Figure 6. SirT3 is essential for $\mathrm{LC}$ nuclear Fox03a and upregulation of PGC-1 $\alpha$ in response to Sh Wake. A, Mid-LC confocal images of TH ${ }^{+}$(red) $\mathrm{LCns}$ with Fox03a (green) across three sleep conditions. FOX03a is evident in nuclei and somata of $\mathrm{LCns}$. B, Mean \pm SE percentage of $\mathrm{TH}^{+} \mathrm{LCns}$ with nuclear Fox03a. Data were analyzed by two-way ANOVA. ${ }^{* * *} p<0.001$. C, Mean $\pm \mathrm{SE}$ integrated intensity of the nuclear Fox03a signal in LCns ( $n=5$ mice/group), analyzed similarly. ${ }^{* *} p<0.01$, ${ }^{* * * *} p<0.0001$. D, Mean \pm SE normalized PGC $-1 \alpha$ immunointensities for the groups ( $n=6$-9/group). ${ }^{*} p<0.05$. E, Immunoblots of PGC- $1 \alpha$ and loading control $\beta$-tubulin in $\mathrm{LC}$ micropunches from SirT3wt and SirT3 ${ }^{-1-}$ mice across the three sleep conditions.

mice $(t=0.2, \mathrm{NS})$. Similarly, wake bout lengths did not vary with genotype $(t=1.9, \mathrm{NS})$, and there was no genotype effect on NREM and REM sleep times $(t=1.3$, NS; and $t=0.2$, NS, respectively). Similarly, there were no differences in NREM and REM sleep bout lengths ( $t=1.1$, NS; and $t=0.0$, NS, respectively). Thus, SirT3 deficiency does not alter basic sleep/wake architecture, as defined by total times and mean bout lengths.

NREM sleep homeostasis defined as an increase in NREMS slow-wave (delta) power is impaired in mice with LCn injury or dysfunction (Cirelli et al., 2005). Genotype mean hourly relative delta power values across baseline sleep in the lights-on period and in response to $6 \mathrm{~h}$ of sleep loss are presented in Figure $8 E$. $\mathrm{SirT}^{-1-}$ mice showed a less pronounced NREMS delta decline across the lights-on period (SirT3wt slope, $-0.033 \pm 0.003$ vs SirT3 $^{-l-}$ slope, $\left.-0.012 \pm 0.003 ; t=4.9, p<0.001\right)$. Relative delta power was significantly higher in SirT3wt mice for ZT1ZT3 and ZT5, for which statistical $t$ values were 2.9-3.9 $(p<$
0.05). In SirT3 ${ }^{-1-}$ mice relative to SirT3wt mice, there were also reductions in the relative delta power for the first $2 \mathrm{~h}$ of recovery NREM sleep after $6 \mathrm{~h}$ of wakefulness, with $t$ values of 2.3-3.1 ( $p<$ 0.05). Thus, SirT3 deficiency is associated with NREMS delta decline in baseline sleep and a blunted NREMS delta response to sleep loss consistent with LC dysfunction effects on sleep homeostasis.

Both sleep/wake conditions and SirT3 genotype had significant effects on nuclear c-fos in LCns. Specifically, SirT3wt mice demonstrated a robust increase in the percentage of LCns with nuclear c-fos in response to the novel environment $(t=9.0, p<0.001$; Fig. $8 F, G)$. A response was also observed in SirT3 ${ }^{-1-}$ mice in response to the novel environment $(t=3.0, p<0.05)$, but the overall c-fos activation was far lower in SirT3 ${ }^{-1-}$ mice compared with SirT3wt mice exposed to the novel environment $(t=6.9 p<0.001)$. In contrast, under Rest conditions there were no differences in $c$-fos activation $(t=0.6, \mathrm{NS})$. In summary, SirT3 ${ }^{-1-}$ mice demonstrate an impaired c-fos activation response to a novel environment. 

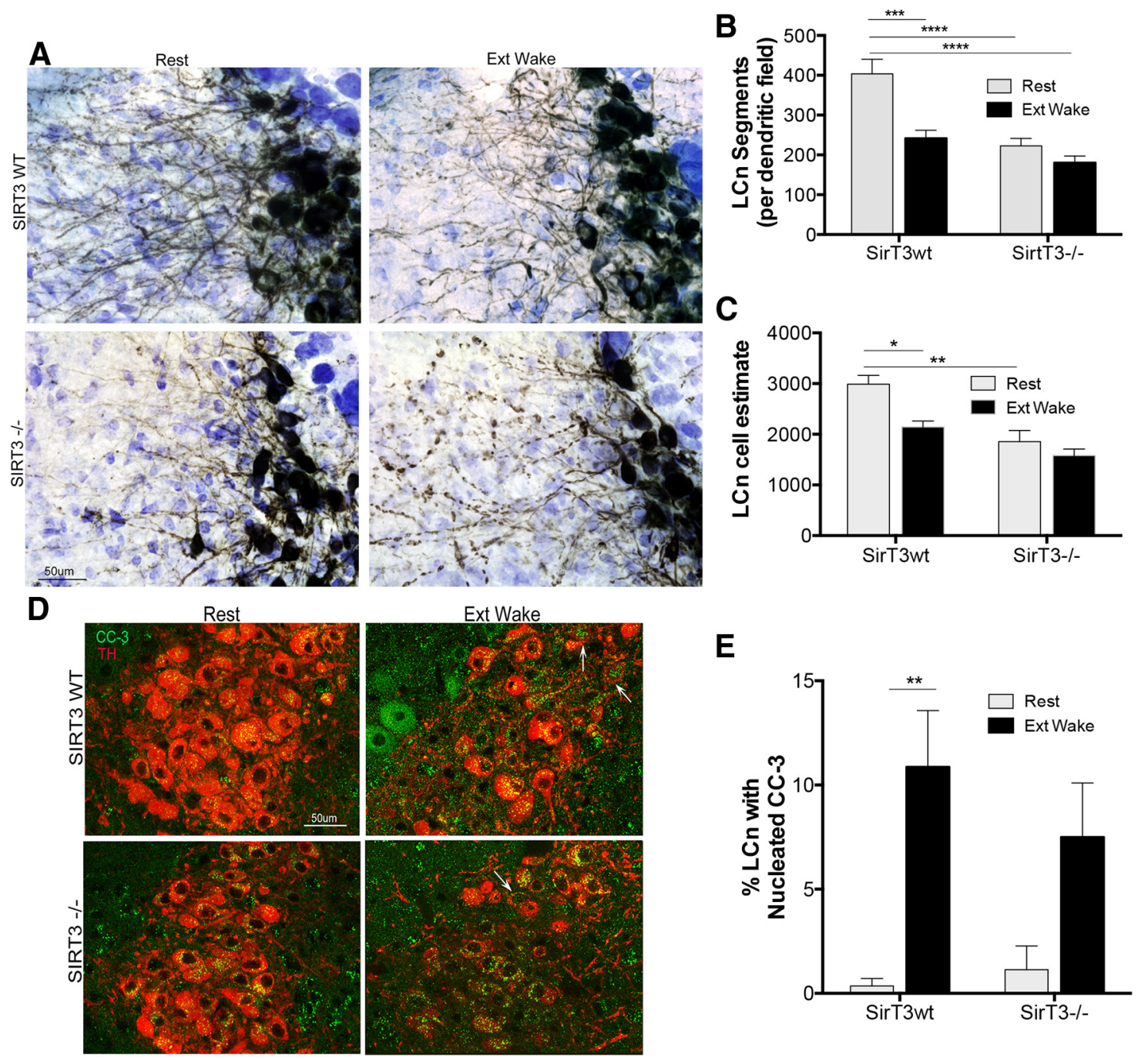

Figure 7. Extended sleep loss results in $\mathrm{LCn}$ dendrite and somata loss, and upregulation of apoptosis in remaining $\mathrm{LCns}$. $A$, Representative ventral lateral $\mathrm{LCn}$ images from $60 \mu \mathrm{m}$ sections with TH (DAB, brown) and Giemsa (blue) labeling demonstrate the effects of sleep loss and SirT3 genotype on LCn dendrites and somata. SirT3 ${ }^{-1-}$ mice exposed to Ext Wake reveal prominent beading of dendrites with vacuolization. $\boldsymbol{B}$, Mean \pm SE group data ( $n=5 /$ group) for dendrite complexity in Rest and Ext Wake for SirT3wt and SirT3 ${ }^{-1-}$ mice analyzed by two-way ANOVA. ${ }^{* * *} p<0.001$; ${ }^{* * * *} p<0.0001$. C, Stereological LCn estimates (bilateral) using optical fractionator for complete LC bilaterally. Data were analyzed with two-way ANOVA $\left(n=5 /\right.$ group). ${ }^{*} p<0.05$; ${ }^{* *} p<0.01$. $\boldsymbol{D}$, Representative confocal image $(0.7 \mu \mathrm{m})$ to localize CC3 (green) within the nuclei of LCns (TH, red). Arrows delineate examples of CC3 labeling within nuclei. Scale bar, $50 \mu \mathrm{m}$. $\boldsymbol{E}$, Mean \pm SE group data ( $n=5 /$ group) for CC3 in Rest (gray) and Ext Wake (black) conditions for SirT3wt and ${ }^{-1-}$ mice also analyzed with two-way ANOVA. ${ }^{* *} p<0.01$.

\section{Discussion}

Impaired cognitive performance following sleep loss is widely believed to occur as a consequence of increased adenosinergic and cytokine signaling that fully reverses with recovery sleep (Ingiosi et al., 2013). The concept that neurons succumb to oxidative stress upon sleep loss has been tested, primarily, in heterogeneous populations of neurons within the frontal or hippocampal cortices or the entire brainstem, and in aggregate brain tissue injury has not been identified (Gopalakrishnan et al., 2004). The present studies were designed to test the following hypotheses: (1) that wakefulness is a significant metabolic stressor to select wakeactivated neurons, in particular LCns; (2) that across short-term sleep loss, mitochondrial sirtuin activation protects LCn metabolic homeostasis; and (3) that upon longer durations of wakefulness this protective response fails, resulting in injury to and loss of LCns.

Injury to LCns negatively impacts diverse aspects of cognitive processing and brain health (Usher et al., 1999; Sara, 2009). LCns provide the sole noradrenergic innervation for cerebral, cerebel- lar, and hippocampal cortices (Pickel et al., 1974; Morrison et al., 1978). Delivered primarily through varicosities, cortical noradrenaline from LCns not only promotes increased neuronal activity, but coordinates increased energy production in adjacent astrocytes and reduced microglial inflammatory responses (O’Donnell et al., 2012). Injury to LCns accelerates neurodegeneration in animal models of Alzheimer's and Parkinson's diseases (Nishi et al., 1991; Marien et al., 1993; Rey et al., 2012). In the present study, we found that Ext Wake resulted in a loss of LCns and strong nuclear labeling of cleaved caspase in a subset of the remaining LCns. Thus, Ext Wake results in substantive LCn injury. While it is difficult to discern whether the loss of LCns and injury of this magnitude are sufficient to result in cognitive impairments, we propose that repeated occurrences of Ext Wake (as is commonly observed in night shift workers) could result in a cumulative loss of LCns that would be sufficient to influence cognition and neurodegenerative processes, in predisposed individuals, as changes in SirT3, FoxO3a, and $\mathrm{O}_{2}^{-\cdot}$ were evident in the majority of remaining LCns in Ext Wake. 
A

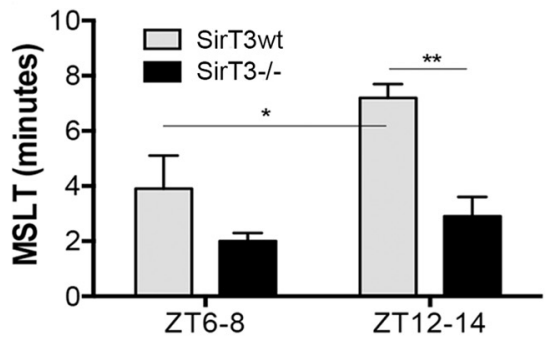

C

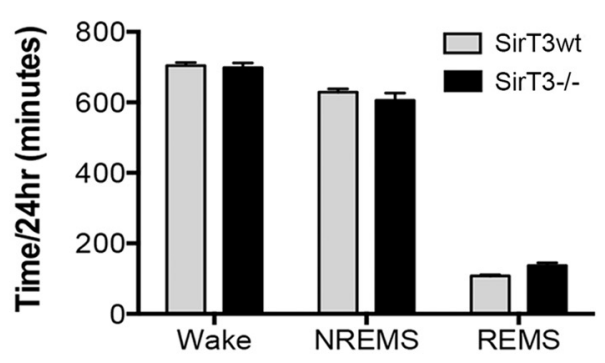

E

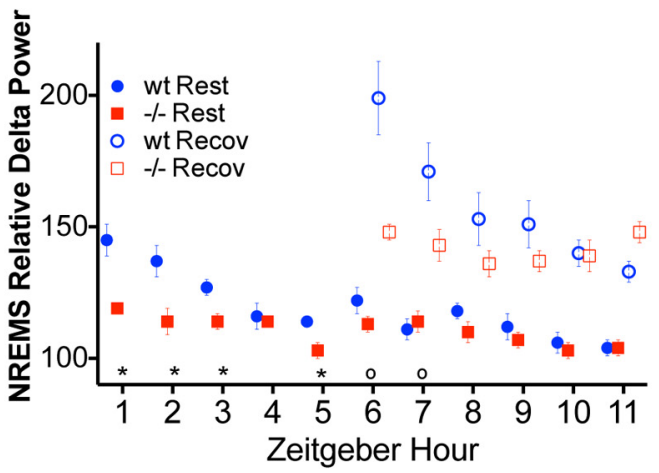

G SirT3wt Rest

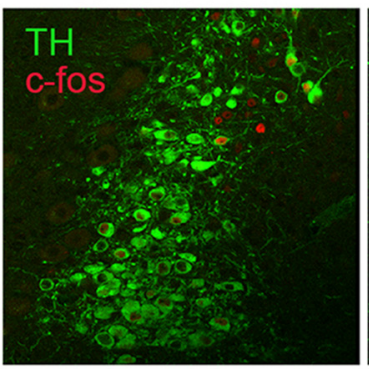

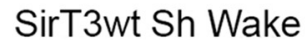

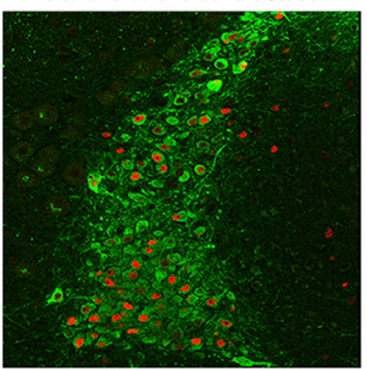

B

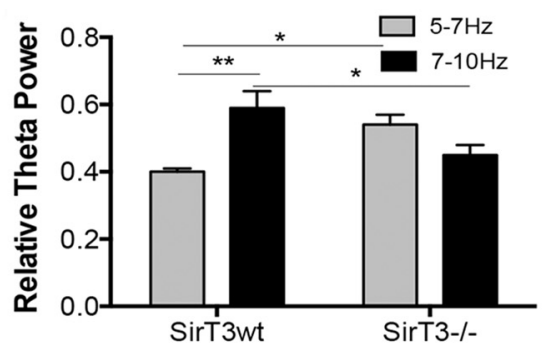

D

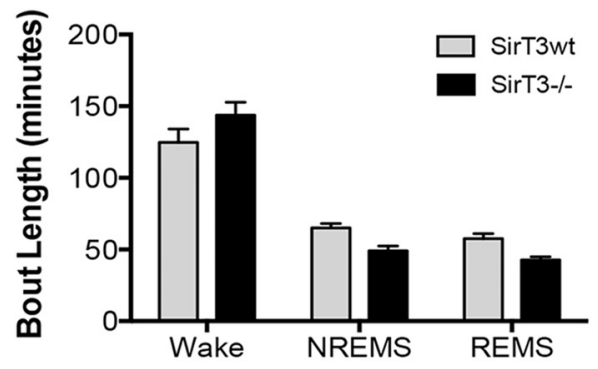

F

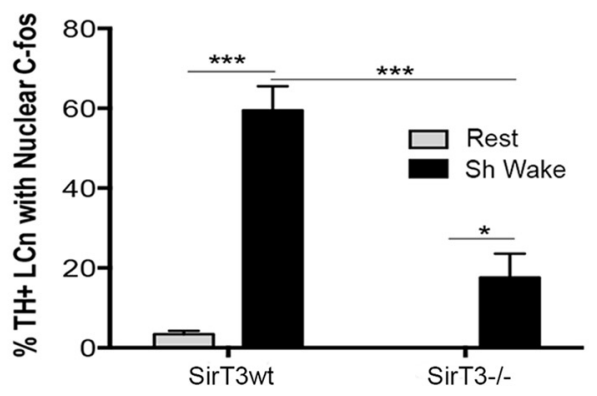

SirT3-/- Rest

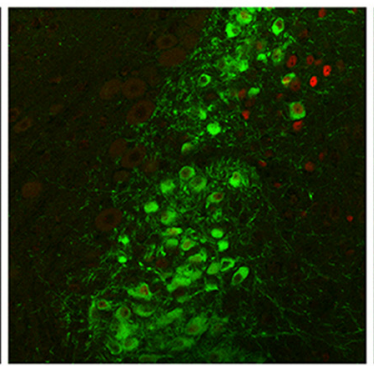

Figure 8. Mice lacking SirT3 show impairments in wakefulness and NREM sleep homeostasis. A, Group average sleep latencies (mean \pm SE, $n=8 /$ group) in a murine MSLT during Zeitgeber hours (relative to lights-on) ZT6-ZT8 and ZT12-ZT14 for SirT3wt (gray) and SirT3 ${ }^{-1-}$ (black) as analyzed with two-way ANOVA. ${ }^{*} p<0.05$; ${ }^{* *} p<0.01$. B, Shown are mean \pm SE relative theta power in slower and faster frequencies: $5-7 \mathrm{~Hz}$ (gray bars) and $7-10 \mathrm{~Hz}$ (black bars), respectively, in response to cage change for SirT3wt and SirT3 ${ }^{-/-}$mice; two-way ANOVA. ${ }^{*} p<0.05 ;{ }^{* *} p<$ 0.01. C, Total time per $24 \mathrm{~h}$ spent in the Wake, NREMS, and REMS conditions for SirT3wt (gray) and SirT3 ${ }^{-1-}$ (black). Two-way ANOVA, NS. D, Average time for each behavioral state bout (minutes) across $24 \mathrm{~h}$ for Wake, NREMS, and REMS conditions for SirT3wt (gray) and SirT3 $3^{-1-}$ (black), NSE, Group (mean \pm SE) relative NREMS delta power for each zeitgeber hour across the lights-on period normalized to the delta power of the last hour of the lights-on period for SirT3wt (blue closed circles) and SirT3 ${ }^{-1-}$ mice (red closed squares). The NREM sleep homeostatic responses to $6 \mathrm{~h}$ wake are shown for SirT $3^{-1-}$ mice (open red squares) and SirT3wt mice (open blue circles) for the first $6 \mathrm{~h}$ of rebound sleep: ${ }^{*} p<0.05$, Bonferroni-corrected differences across baseline; $p<0.05$, for differences across recovery sleep. $F$, Summary data for the percentage of $\mathrm{TH}^{+}$neurons in $\mathrm{L}$ C nucleus with nuclear c-fos labeling for conditions Rest (light gray) and Sh Wake (black) in both SirT3wt and SirT3 ${ }^{-I-}$ mice. Data were analyzed with two-way ANOVA. ${ }^{* * *} p<0.001$. G, Representative images of c-fos in the LC. Shown are confocal images $1 \mu \mathrm{m}$ thick to delineate nuclear labeling of c-fos (red) within TH (green)-labeled LCns.

We anticipated that mice lacking SirT3 would show an even greater loss of LCns in response to Ext Wake. At baseline, however, these mice revealed a $30 \%$ loss of LCns, a smaller dendritic field, and minimal c-fos activation across wakefulness. Thus, LCns in mice lacking SirT3 may have reduced metabolic demands across wakefulness, relative to wild-type mice. Alterna- tively, susceptible LCns may have been lost in SirT3 ${ }^{-/-}$mice before Ext Wake. In response to Ext Wake, SirT3 ${ }^{-1-}$ mice did display marked neurite beading with vacuolization. Neurite dystrophy, including beading, is observed in diverse neuronal injuries, including ischemia, Alzheimer's disease, Parkinson's disease, and amyotrophic lateral sclerosis, and is considered to 
contribute to neuronal demise (McMurray, 2000). In a model of excitotoxicity, the severity of neuritic beading predicts neuronal loss (Takeuchi et al., 2005). A longer observational period may be necessary to appreciate Ext Wake-induced neuronal loss in $\mathrm{SirT}^{-1-}$ mice.

Sleep deprivation is an important tool with which to gain insight into the functions and neurobiology of sleep, but this approach can also be a source of stress in laboratory animals, where stress may confound the interpretation of results. Placing animals atop small platforms from which they fall upon sleeping can increase plasma corticosterone levels twofold (Machado et al., 2013), as can repeatedly tapping on cages and brushing quiescent animals within their own cage (Tobler et al., 1983). In the present study, efforts were made to minimize stress by allowing mice spontaneous wakefulness in an enriched environment equipped with climbing objects, novel nesting materials, and littermates. Overall, we observed no significant increase in plasma corticosterone levels for either Sh or Ext Wake. Moreover, plasma levels in Ext Wake tended to be lower than those in Sh Wake, and yet injury was observed only in mice exposed to Ext Wake. Thus, it is unlikely that the sleep loss injury effects observed in LCns can be attributed to stress.

Remarkably, we observed that endogenous SirT3 is essential for maintaining redox homeostasis in LCns across a period of just several hours of wakefulness within the habitual sleeping period. The necessity of SirT3 to maintain redox homeostasis supports the concept that short-term sleep loss is a metabolic stressor for LCns, and that mitochondria contribute to the homeostatic response to sleep loss. By upregulating FoxO3a, PGC- $1 \alpha$, and antioxidant enzymes, this homeostatic response is expected to render LCns more resistant to metabolic disturbances. The mechanisms by which SirT3 results in increased FoxO3a, PGC$1 \alpha$, SOD2, and catalase levels are not known. The nuclear translocation of FoxO3a and transcriptional upregulation of antioxidant enzymes support a SirT3-regulated mitochondriato-nucleus communication in response to Sh Wake. An alternative explanation for SirT3-mediated changes in protein levels may involve effects on protein stability where deacetylation promotes ubiquitination and, thus, protein clearance (Caron et al., 2005). Mitochondrially localized SirT3, however, should not affect catalase, NAMPT, or PGC- $1 \alpha$ stability, and cytosolic protein acetylation was not changed in response to Sh Wake. Thus, a more likely source of Sh Wake antioxidants is SirT3-dependent Foxo3a activation and/or upregulation of PGC- $1 \alpha$.

While it may be surprising that $3 \mathrm{~h}$ of wakefulness would require an antioxidant response to offset oxidative stress, it is important to remember that LCns, and other wake-active neurons, have great metabolic demands across wakefulness. Noradrenergic LCns demonstrate continuous activity throughout wakefulness, particularly exploratory wakefulness. In support, nuclear c-fos translocation, an index marker of neuronal activity, is increased markedly in LCns of rats exposed to a novel environment (Gompf et al., 2010), as was observed in our SirT3wt mice. In NREM sleep, LC activity declines significantly, and LCn activity approaches complete quiescence in REM sleep (Takahashi et al., 2010). Increased synaptic activity in wakefulness and increased synthesis, packaging, and transport of large amounts of noradrenaline and cotransmitters to cortices require increased ATP production all along neurites, which, in turn, will increase $\mathrm{O}_{2}^{-}$. production at the ETC (Léna et al., 2005). There is some recent evidence that, upon heightened LCn stimulation, as observed with higher-frequency optogenetic stimulation of the LCns, LCn output fails, as measured by cortical noradrenaline
(Carter et al., 2010). Metabolic dyshomeostasis in LCns upon massive or prolonged stimulation is an intriguing possibility for the reduced noradrenaline output despite continued activation. We propose that sleep serves a vital function for LCns, and potentially other neuronal groups, in restoring mitochondrial metabolic homeostasis following wakefulness, thereby allowing normal function across normal periods of wakefulness.

In contrast to the robust SirT3 upregulation and metabolic homeostasis observed in response to Sh Wake in wild-type mice, under conditions of Ext Wake, LCn SirT3 declined, while mitochondrial protein acetylation increased in the LC in SirT3wt mice. Mechanisms underlying the decline in SirT3 protein upon Ext Wake remain elusive. Downregulation of SirT3 protein can occur through oxidative stress-mediated transcriptional repression (D'Aquila et al., 2012). Oxidative stress in aging is believed to contribute to the reduced SirT3 activity underlying age-related hearing loss (Someya et al., 2010). The increased mitochondrial acetylation observed, including complex I acetylation, in Ext Wake is expected to impact negatively on both energy supply and redox homeostasis (Ahn et al., 2008). Thus, while Sh Wake may render LCns more resistant to added oxidative insults, Ext Wake may increase the susceptibility of LCns to additional oxidative stressors. In support, we observed reduced SOD2, catalase, and nuclear FoxO3a, and increased $\mathrm{O}_{2}^{-\cdot}$ levels in LCns in mice exposed to Ext Wake.

A surprising finding in the present study was the threefold increase in cortical cellular $\mathrm{NAD}^{+}$in response to Ext Wake. Increased $\mathrm{NAD}^{+}$could be explained by increased production and/or reduced consumption of $\mathrm{NAD}^{+}$. The rate-limiting enzyme for the $\mathrm{NAD}^{+}$salvage synthesis pathway is NAMPT. Ext Wake reduced NAMPT protein levels in LCns. Thus, intracellular $\mathrm{NAD}^{+}$biosynthesis does not appear to be increased in Ext Wake, although we cannot rule out an increase in the extracellular generation of nicotinamide mononucleotide, which could also contribute to intracellular $\mathrm{NAD}^{+}$pools. Although sirtuins consume $\mathrm{NAD}^{+}$, the major consumers of cytoplasmic NAD ${ }^{+}$are considered to be poly(ADP)-ribosyl polymerases (PARPs) and cADPribose synthases (CD38, CD157). In metabolically active cells, a substantial fraction of cellular $\mathrm{NAD}^{+}$is in mitochondria (Di Lisa and Ziegler, 2001), which contain neither PARPs nor major cADP-ribose synthases. SirT3, therefore, may be a primary consumer of mitochondrial NAD ${ }^{+}$. In support of a SIRT3 influence on $\mathrm{NAD}^{+}$levels, mice lacking SIRT3 had higher $\mathrm{NAD}^{+}$levels at baseline (equivalent to wild-type mice exposed to extended sleep loss), and levels of $\mathrm{NAD}^{+}$did not increase further with Ext Wake in SIRT3 ${ }^{-1-}$ mice.

The divergence in SirT3 responses for Sh and Ext Wake observed in the present study may help explain previously observed, seemingly disparate, metabolic responses to sleep loss in other brain regions. Specifically, upregulation of SirT3 as observed in Sh Wake is expected to promote increased SOD, glutathione, and glutathione peroxidase activities, as previously observed in response to short-term sleep loss (Ramanathan et al., 2010). Similarly, the decreased ATP production, reduced SOD and glutathione peroxidase activities, lower reduced glutathione/oxidized glutathione ratio, and increased malondialdehyde levels in whole brain, cortex, and/or hippocampus previously observed upon long-term sleep deprivation (Silva et al., 2004; Khadrawy et al., 2011) would be expected from reduced SirT3 activity (Ahn et al., 2008; Qiu et al., 2010), as we observed in Ext Wake. In the present study, we observed an increase in mitochondrial acetylation, also in the cortex in response to Ext Wake, supporting the concept that wake duration-dependent changes in SirT3 activity may ex- 
plain the divergent metabolic responses within the brain to shortterm and longer-term sleep loss.

Mice lacking SirT3 demonstrate shortened sleep latencies in the lights-off (active) period, and in response to novel environments SirT3 ${ }^{-1-}$ mice evidence slower theta EEG frequencies and reduced LCn c-fos activation. The blunted homeostatic drive after short-term sleep loss and the impaired c-fos response in LCns to a novel cage are consistent with LCn dysfunction (Cirelli et al., 2005; Carter et al., 2010), supporting a key role for mitochondrial metabolic activities in basal LCn function, while the impaired wakefulness in these mice supports the concept that mitochondrial disorders and mitochondrial dysfunction with aging may contribute to wake impairments and fatigue associated with these conditions.

In conclusion, we find that brief wakefulness activates a mitochondrial response in LCns, including increased SirT3 levels, nuclear translocation of FoxO3a, and upregulation of antioxidant enzymes in LCns, with a resultant maintenance of mitochondrial metabolic homeostasis. This metabolic homeostasis requires SirT3. In contrast, with repeated extended durations of sleep loss, SirT3 activity declines, increasing LCn superoxide production, and LC mitochondrial protein acetylation, including acetylation of ETC complex I. Importantly, Ext Wake is associated with a loss of LCns that occurs, at least in part, through apoptosis. The work shows, for the first time, that extended sleep loss is a metabolic stressor to LCns and that extended wakefulness can result in LCn loss.

\section{References}

Ahn BH, Kim HS, Song S, Lee IH, Liu J, Vassilopoulos A, Deng CX, Finkel T (2008) A role for the mitochondrial deacetylase Sirt3 in regulating energy homeostasis. Proc Natl Acad Sci U S A 105:14447-14452. CrossRef Medline

Andrews ZB, Horvath B, Barnstable CJ, Elseworth J, Yang L, Beal MF, Roth RH, Matthews RT, Horvath TL (2005) Uncoupling protein-2 is critical for nigral dopamine cell survival in a mouse model of Parkinson's disease. J Neurosci 25:184-191. CrossRef Medline

Aston-Jones G, Bloom FE (1981) Activity of norepinephrine-containing locus ceruleus neurons in behaving rats anticipates fluctuations in the sleepwaking cycle. J Neurosci 1:876-886. Medline

Bell EL, Guarente L (2011) The SirT3 divining rod points to oxidative stress. Mol Cell 42:561-568. CrossRef Medline

Blutstein T, Haydon PG (2013) The importance of astrocyte-derived purines in the modulation of sleep. Glia 61:129-139. CrossRef Medline

Caron C, Boyault C, Khochbin S (2005) Regulatory cross-talk between lysine acetylation and ubiquitination: role in the control of protein stability. Bioessays 27:408-415. CrossRef Medline

Carter ME, Yizhar O, Chikahisa S, Nguyen H, Adamantidis A, Nishino S, Deisseroth K, de Lecea L (2010) Tuning arousal with optogenetic modulation of locus coeruleus neurons. Nat Neurosci 13:1526-1533. CrossRef Medline

Centers for Disease Control and Prevention (2012) Short sleep duration among workers-United States, 2010. MMWR Morb Mortal Wkly Rep 61:281-285. Medline

Cirelli C, Huber R, Gopalakrishnan A, Southard TL, Tononi G (2005) Locus ceruleus control of slow-wave homeostasis. J Neurosci 25:4503-4511. CrossRef Medline

D’Aquila P, Rose G, Panno ML, Passarino G, Bellizzi D (2012) SIRT3 gene expression: a link between inherited mitochondrial DNA variants and oxidative stress. Gene 497:323-329. CrossRef Medline

Di Lisa F, Ziegler M (2001) Pathophysiological relevance of mitochondria in NAD $(+)$ metabolism. FEBS Lett 492:4-8. CrossRef Medline

Fritz KS, Galligan JJ, Smathers RL, Roede JR, Shearn CT, Reigan P, Petersen DR (2011) 4-Hydroxynonenal inhibits SIRT3 via thiol-specific modification. Chem Res Toxicol 24:651-662. CrossRef Medline

Gompf HS, Mathai C, Fuller PM, Wood DA, Pedersen NP, Saper CB, Lu J (2010) Locus ceruleus and anterior cingulate cortex sustain wakefulness in a novel environment. J Neurosci 30:14543-14551. CrossRef Medline
Gopalakrishnan A, Ji LL, Cirelli C (2004) Sleep deprivation and cellular responses to oxidative stress. Sleep 27:27-35. Medline

Graeff R, Lee HC (2002) A novel cycling assay for cellular cADP-ribose with nanomolar sensitivity. Biochem J 361:379-384. Medline

He W, Newman JC, Wang MZ, Ho L, Verdin E (2012) Mitochondrial sirtuins: regulators of protein acylation and metabolism. Trends Endocrinol Metab 23:467-476. CrossRef Medline

Hu D, Serrano F, Oury TD, Klann E (2006) Aging-dependent alterations in synaptic plasticity and memory in mice that overexpress extracellular superoxide dismutase. J Neurosci 26:3933-3941. CrossRef Medline

Ingiosi AM, Opp MR, Krueger JM (2013) Sleep and immune function: glial contributions and consequences of aging. Curr Opin Neurobiol 23:806811 CrossRef Medline

Jacobs KM, Pennington JD, Bisht KS, Aykin-Burns N, Kim HS, Mishra M, Sun L, Nguyen P, Ahn BH, Leclerc J, Deng CX, Spitz DR, Gius D (2008) SIRT3 interacts with the daf- 16 homolog FoxO3a in the mitochondria, as well as increases FoxO3a dependent gene expression. Int J Biol Sci 4:291299. CrossRef Medline

Khadrawy YA, Nour NA, Aboul Ezz HS (2011) Effect of oxidative stress induced by paradoxical sleep deprivation on the activities of $\mathrm{Na}+, \mathrm{K}+-$ ATPase and acetylcholinesterase in the cortex and hippocampus of rat. Transl Res 157:100-107. CrossRef Medline

Kops GJ, Dansen TB, Polderman PE, Saarloos I, Wirtz KW, Coffer PJ, Huang TT, Bos JL, Medema RH, Burgering BM (2002) Forkhead transcription factor FoxO3a protects quiescent cells from oxidative stress. Nature 419: 316-321. CrossRef Medline

Léger L, Goutagny R, Sapin E, Salvert D, Fort P, Luppi PH (2009) Noradrenergic neurons expressing Fos during waking and paradoxical sleep deprivation in the rat. J Chem Neuroanat 37:149-157. CrossRef Medline

Léna I, Parrot S, Deschaux O, Muffat-Joly S, Sauvinet V, Renaud B, SuaudChagny MF, Gottesmann C (2005) Variations in extracellular levels of dopamine, noradrenaline, glutamate, and aspartate across the sleep-wake cycle in the medial prefrontal cortex and nucleus accumbens of freely moving rats. J Neurosci Res 81:891-899. CrossRef Medline

Machado RB, Tufik S, Suchecki D (2013) Role of corticosterone on sleep homeostasis induced by REM sleep deprivation in rats. PLoS One 8:e63520. CrossRef Medline

Marien M, Briley M, Colpaert F (1993) Noradrenaline depletion exacerbates MPTP-induced striatal dopamine loss in mice. Eur J Pharmacol 236:487-489. CrossRef Medline

McCoy JG, Strecker RE (2011) The cognitive cost of sleep lost. Neurobiol Learn Mem 96:564-582. CrossRef Medline

McMurray CT (2000) Neurodegeneration: diseases of the cytoskeleton? Cell Death Differ 7:861-865. CrossRef Medline

Morrison JH, Grzanna R, Molliver ME, Coyle JT (1978) The distribution and orientation of noradrenergic fibers in neocortex of the rat: an immunofluorescence study. J Comp Neurol 181:17-39. CrossRef Medline

Murai Y, Ishibashi H, Koyama S, Akaike N (1997) Ca2+-activated K+ currents in rat locus coeruleus neurons induced by experimental ischemia, anoxia, and hypoglycemia. J Neurophysiol 78:2674-2681. Medline

Nikonova EV, Vijayasarathy C, Zhang L, Cater JR, Galante RJ, Ward SE, Avadhani NG, Pack AI (2005) Differences in activity of cytochrome C oxidase in brain between sleep and wakefulness. Sleep 28:21-27. Medline

Nikonova EV, Naidoo N, Zhang L, Romer M, Cater JR, Scharf MT, Galante RJ, Pack AI (2010) Changes in components of energy regulation in mouse cortex with increases in wakefulness. Sleep 33:889-900. Medline

Nishi K, Kondo T, Narabayashi H (1991) Destruction of norepinephrine terminals in 1-methyl-4-phenyl-1,2,3,6-tetrahydropyridine (MPTP)treated mice reduces locomotor activity induced by L-dopa. Neurosci Lett 123:244-247. CrossRef Medline

O’Donnell J, Zeppenfeld D, McConnell E, Pena S, Nedergaard M (2012) Norepinephrine: a neuromodulator that boosts the function of multiple cell types to optimize CNS performance. Neurochem Res 37:2496-2512. CrossRef Medline

Olmos Y, Valle I, Borniquel S, Tierrez A, Soria E, Lamas S, Monsalve M (2009) Mutual dependence of Foxo3a and PGC-1alpha in the induction of oxidative stress genes. J Biol Chem 284:14476-14484. CrossRef Medline

Panossian L, Fenik P, Zhu Y, Zhan G, McBurney MW, Veasey S (2011) SIRT1 regulation of wakefulness and senescence-like phenotype in wake neurons. J Neurosci 31:4025-4036. CrossRef Medline

Pickel VM, Segal M, Bloom FE (1974) A radioautographic study of the ef- 
ferent pathways of the nucleus locus coeruleus. J Comp Neurol 155:1542. CrossRef Medline

Qiu X, Brown K, Hirschey MD, Verdin E, Chen D (2010) Calorie restriction reduces oxidative stress by SIRT3-mediated SOD2 activation. Cell Metab 12:662-667. CrossRef Medline

Ramanathan L, Gulyani S, Nienhuis R, Siegel JM (2002) Sleep deprivation decreases superoxide dismutase activity in rat hippocampus and brainstem. Neuroreport 13:1387-1390. CrossRef Medline

Ramanathan L, Hu S, Frautschy SA, Siegel JM (2010) Short-term total sleep deprivation in the rat increases antioxidant responses in multiple brain regions without impairing spontaneous alternation behavior. Behav Brain Res 207:305-309. CrossRef Medline

Rey NL, Jardanhazi-Kurutz D, Terwel D, Kummer MP, Jourdan F, Didier A, Heneka MT (2012) Locus coeruleus degeneration exacerbates olfactory deficits in APP/PS1 transgenic mice. Neurobiol Aging 33:426.el-e11. Medline

Sara SJ (2009) The locus coeruleus and noradrenergic modulation of cognition. Nat Rev Neurosci 10:211-223. CrossRef Medline

Shipley MT, Fu L, Ennis M, Liu WL, Aston-Jones G (1996) Dendrites of locus coeruleus neurons extend preferentially into two pericoerulear zones. J Comp Neurol 365:56-68. CrossRef Medline

Silva RH, Abílio VC, Takatsu AL, Kameda SR, Grassl C, Chehin AB, Medrano WA, Calzavara MB, Registro S, Andersen ML, Machado RB, Carvalho RC, Ribeiro Rde A, Tufik S, Frussa-Filho R (2004) Role of hippocampal oxidative stress in memory deficits induced by sleep deprivation in mice. Neuropharmacology 46:895-903. CrossRef Medline

Someya S, Yu W, Hallows WC, Xu J, Vann JM, Leeuwenburgh C, Tanokura M, Denu JM, Prolla TA (2010) Sirt3 mediates reduction of oxidative damage and prevention of age-related hearing loss under caloric restriction. Cell 143:802-812. CrossRef Medline

Sundaresan NR, Gupta M, Kim G, Rajamohan SB, Isbatan A, Gupta MP (2009) Sirt3 blocks the cardiac hypertrophic response by augmenting Foxo3a-dependent antioxidant defense mechanisms in mice. J Clin Invest 119:2758-2771. CrossRef Medline

Takahashi K, Kayama Y, Lin JS, Sakai K (2010) Locus coeruleus neuronal activity during the sleep-waking cycle in mice. Neuroscience 169:11151126. CrossRef Medline

Takeuchi H, Mizuno T, Zhang G, Wang J, Kawanokuchi J, Kuno R, Suzumura
A (2005) Neuritic beading induced by activated microglia is an early feature of neuronal dysfunction toward neuronal death by inhibition of mitochondrial respiration and axonal transport. J Biol Chem 280:1044410454. CrossRef Medline

Tobler I, Murison R, Ursin R, Ursin H, Borbély AA (1983) The effect of sleep deprivation and recovery sleep on plasma corticosterone in the rat. Neurosci Lett 35:297-300. CrossRef Medline

Tseng AH, Shieh SS, Wang DL (2013) SIRT3 deacetylates FOXO3 to protect mitochondria against oxidative damage. Free Radic Biol Med 63:222-234. CrossRef Medline

Usher M, Cohen JD, Servan-Schreiber D, Rajkowski J, Aston-Jones G (1999) The role of locus coeruleus in the regulation of cognitive performance. Science 283:549-554. CrossRef Medline

Vankov A, Hervé-Minvielle A, Sara SJ (1995) Response to novelty and its rapid habituation in locus coeruleus neurons of the freely exploring rat. Eur J Neurosci 7:1180-1187. CrossRef Medline

Veasey SC, Valladares O, Fenik P, Kapfhamer D, Sanford L, Benington J, Bucan M (2000) An automated system for recording and analysis of sleep in mice. Sleep 23:1025-1040. Medline

Veasey SC, Yeou-Jey H, Thayer P, Fenik P (2004) Murine Multiple Sleep Latency Test: phenotyping sleep propensity in mice. Sleep 27:388-393. Medline

Vyazovskiy VV, Tobler I (2005) Theta activity in the waking EEG is a marker of sleep propensity in the rat. Brain Res 1050:64-71. CrossRef Medline

Wagner GR, Pride PM, Babbey CM, Payne RM (2012) Friedreich's ataxia reveals a mechanism for coordinate regulation of oxidative metabolism via feedback inhibition of the SIRT3 deacetylase. Hum Mol Genet 21: 2688-2697. CrossRef Medline

West MJ, Gundersen HJ (1990) Unbiased stereological estimation of the number of neurons in the human hippocampus. J Comp Neurol 296:122. CrossRef Medline

Yu W, Dittenhafer-Reed KE, Denu JM (2012) SIRT3 protein deacetylates isocitrate dehydrogenase 2 (IDH2) and regulates mitochondrial redox status. J Biol Chem 287:14078-14086. CrossRef Medline

Zhu Y, Fenik P, Zhan G, Mazza E, Kelz M, Aston-Jones G, Veasey SC (2007) Selective loss of catecholaminergic wake active neurons in a murine sleep apnea model. J Neurosci 27:10060-10071. CrossRef Medline 